\title{
Photodecomposition Properties of Brominated Flame Retardants
} (BFRs)

\author{
Anam Saeed $^{\mathrm{a}}$, Mohammednoor Altarawneh ${ }^{\mathrm{a}, *}$, Kamal Siddique ${ }^{\mathrm{a}}$, Juan A. Conesa ${ }^{\mathrm{b}}$, \\ Nuria Ortuño ${ }^{b}$ and Bogdan Z. Dlugogorski ${ }^{a}$
}

${ }^{a}$ School of Engineering and Information Technology, Murdoch University 90 South Street, Murdoch, WA 6150, Australia

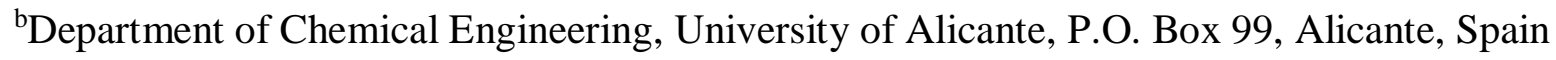

*Corresponding author:

Phone: +61 89360 7507, Email: M.Altarawneh@murdoch.edu.au 


\section{Abstract}

This study investigates the geometric and electronic properties of selected BFRs in their ground $\left(\mathrm{S}_{0}\right)$ and first singlet excited $\left(\mathrm{S}_{1}\right)$ states deploying methods of the density functional theory (DFT) and the time-dependent density functional theory (TDDFT). We estimate the effect of the $S_{0} \rightarrow S_{1}$ transition on the elongations of the $\mathrm{C}-\mathrm{Br}$ bond, identify the frontier molecular orbitals involved in the excitation process and compute partial atomic charges for the most photoreactive bromine atoms. The bromine atom attached to an ortho position in HBB (with regard to C-C bond; $2,2^{\prime}, 4,4^{\prime}, 6,6^{\prime}$-hexabromobiphenyl), TBBA (with respect to the hydroxyl group; 2,2',6,6'-tetrabromobisphenol A), HBDE and BTBPE (in reference to C-O linkage; 2,2',4,4',6,6'-hexabromodiphenylether and 1,2-bis(2,4,6-tribromophenoxy)ethane, respectively) bears the highest positive atomic charge. This suggests that, these positions undergo reductive debromination reactions to produce lower brominated molecules. Debromination reactions ensue primarily in the aromatic compounds substituted with the highest number of bromine atoms owing to the largest stretching of the $\mathrm{C}$-Br bond in the first excited state. The analysis of the frontier molecular orbitals indicates that, excitations of BFRs proceed via $\pi \rightarrow \pi^{*}$, or $\pi \rightarrow \sigma^{*}$ or $n \rightarrow \sigma^{*}$ electronic transitions. The orbital analysis reveals that, the HOMO-LUMO energy gap $\left(E^{\mathrm{H}-\mathrm{L}}\right)$ for all investigated bromine-substituted aromatic molecules falls lower $(1.85-4.91 \mathrm{eV})$ than for their non-brominated analogues $(3.39-8.07$ $\mathrm{eV}$ ), in both aqueous and gaseous media. The excitation energies correlate with the $E^{\mathrm{H}-\mathrm{L}}$ values. The excitation energies and $E^{\mathrm{H}-\mathrm{L}}$ values display a linear negative correlation with the number of bromine atoms attached to the molecule. Spectral analysis of the gaseous-phase systems reveals that, the highly brominated aromatics endure lower excitation energies and exhibit red shifts of their absorption bands in comparison to their lower brominated congeners. We attained a satisfactory agreement between the experimentally measured absorption peak $\left(\lambda_{\max }\right)$ 
and the theoretically predicted oscillator strength $\left(\lambda_{\max }\right)$ for the UV-Vis spectra. This study further confirms that, halogenated aromatics only absorb light in the UV spectral region and that effective photodegradation of these pollutants requires the presence of photocatalysts.

\section{Key words}

Brominated flame retardants (BFRs); Time dependent density functional theory (TDDFT), Photodegradation, Geometric and electronic properties, Excited states. 


\section{Introduction}

Brominated flame retardants (BFRs) comprise bromine-bearing hydrocarbons commonly added to the polymeric constituents in consumer products to enhance their fire retardancy. In light of their substantial deployment over the past two decades, BFRs have accumulated in various environmental compartments spaning sewage sludge, sediments (Sellström et al., 1999; Morris et al., 2004), air samples and water bodies (Covaci et al., 2003; Eljarrat et al., 2005; Möller et al., 2011). While the historically-employed BFRs persist in the environment, recent investigations have revealed alarming concentrations of the so-called novel BFRs (Ali et al., 2011a,b; Covaci et al., 2011; de Wit, 2002; Eriksson et al., 2001; Fromme et al., 2014).

The bioaccumulative and persistent nature of BFRs renders them as one of the main themes of research among environmental chemists. High concentrations of certain BFRs are adequate to provoke toxic effects in humans and wildlife (Darnerud, 2003; Watanabe and Sakai, 2003). While BFRs can be toxic in their own right, the major environmental burden of BFRs rests on their structural functionality as direct building blocks for the generation of notorious polybrominated dibenzo-p-dioxins and dibenzofurans (PBDD/Fs) (Buser, 1986; Luijk and Govers, 1992; Sakai et al., 2001; Weber and Kuch, 2003). As the thermal treatment represents a mainstream strategy in recovery and disposal of materials laden with BFRs (i.e., plastics and electronic wastes), several studies have elucidated scenarios and pathways underpinning the transformation of BFRs into PBDD/Fs at elevated temperatures relevant to "waste-to-energy" applications (Altarawneh and Dlugogorski, 2013, 2014a,b, 2015). In addition to formation of PBDD/Fs, the thermal decomposition of BFRs generates a wide array of small brominated $\mathrm{C}_{1}$ -

$\mathrm{C}_{4}$ species as well as large macromolecules (Barontini and Cozzani, 2006; Barontini et al., 2004; Luda et al., 2002; Ortuño et al., 2014; Saeed et al., 2015, 2016a). 
BFRs enter the environment via several routes, most notably, through direct diffusion from treated objects at room temperature (Choi et al., 2009; Stapleton et al., 2011) and from open burning and dumping of BFR-containing materials (Gullett et al., 2007; Eguchi et al., 2013; Tian et al., 2011). This makes it important to trace down the chemical transformation pathways of BFRs in the environment. While thermal processes decontaminate BFRs by destroying their structures, pathways prevailing in the environment are fundamentally distinct.

Photolysis constitute the primary environmental route for the chemical transformation of BFRs. Most relevant experimental investigations have focused on the photo-induced decay of polybrominated diphenyl ethers (PBDEs). Söderström et al. investigated photolysis of decaBDE in different environmental matrices (Söderström et al., 2004). Various sunlight conditions induce the formation of lower brominated congeners of diphenylethers, especially the lower isomers of PBDEs and PBDFs. The medium of reaction (i.e., solid, sediment and sand) exhibits little influence on the debromination process, however, it significantly affects the temporal scale of the reaction. Few studies (Eriksson et al., 2004; Watanabe and Tatsukawa, 2008; Norris et al., 1973) consistently reported the debromination during the course of photolysis of PBDEs. Eriksson et al. (2004) observed different isomers of PBDEs exhibiting distinct photolytic decay rates. Similarly, experiments of Otha et al. (2001) established that, different sources of light (sunlight versus UV-lamps) produce diverse patterns of debrominated products.

Theoretical calculations based on the time-dependent density functional theory (TDDFT) formalism elucidated structures and electronic properties of various BFRs at their first excited states, as function of their photoreactivity (Luo et al., 2015; Sun et al., 2013; Suh et al., 2009; 
Wang et al., 2012). These investigations assessed (i) the transformation of brominated moieties in their singlet or triplet excited states and (ii) the effect of the degree and pattern of bromination on the photodecomposition processes. Along this line of inquiry, in our recent theoretical contribution, we have computed properties of the complete series of bromophenols (BPhs) in their ground and first excited states (Saeed et al., 2016b). Our results articulate that, when brominated compounds become photoexcited, the rate of debromination follows the sequence of ortho>meta>para positions. Furthermore, congeners entailing a high degree of bromination demand lower excitation energies and photodecompose more readily than the lower brominated isomers. Thus, the reductive photodebromination depends on the pattern and degree of bromine substituents on the aromatic ring.

Brominated aromatic compounds, in general, absorb light in the UV region. Sufficient amount of captured electromagnetic energy triggers a facile homolytic fission of $\mathrm{C}-\mathrm{Br}$ bond and provokes structural rearrangements, including cleavage of the ether bond. Mechanistically, the UV energy absorbed in a molecule prompts the appearance of two pathways (i) a large fraction of energy engenders electron transitions between $\pi$ and $\pi^{*}$ and between $n$ and $\sigma^{*}$ orbitals, (ii) whereas the remainder induces the rupture of the C-Br bonds (Joschek and Miller, 1966). In a nutshell, photoexcited BFRs undergo singlet or triplet excited state transitions that involve weakening of the aromatic $\mathrm{C}-\mathrm{Br}$ bonds.

While daylight has no capacity to photodecompose neat BFRs, certain species in the aqueous medium can act as photocatalysts. A pioneering study by Sun et al. has demonstrated the role of carboxylate anions to mediate reductive debromination of PBDEs in visible light (Sun et al., 2103). The BFRs probably coexist with organic acids in the environment. For example, the 
hydrophobic nature of BFRs facilitates their adsorption in the outer waxy surfaces of plants and even on human skin (Jaward et al., 2004; Mimmoa et al., 2011).

The reported reductive debromination of BFRs in the ambient environment has motivated us to study the properties of selected BFRs on the verge of their photodecomposition. To this end, the current contribution elucidates results of DFT and TDDFT calculations designed to evaluate the photodecomposition behaviour of the most commonly deployed BFRs as function of degree of bromination. Investigated BFRs include polybrominated biphenyls, polybrominated diphenylethers, polybrominated bisphenols, 1,2-bis $(2,4,6-$ tribromophenoxy)ethane and bromocyclododecane. To study the effect of degree of bromination, we selected hexa, tetra and dibrominated congeners of biphenyls and

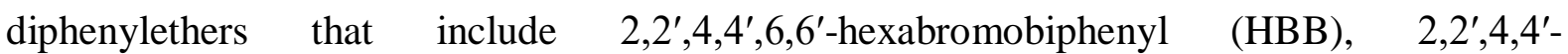
tetrabromobiphenyl (TBB) and 4,4'-dibromobiphenyl (DBB), 2,2',4,4',6,6'hexabromodiphenylether (HBDE), 2,2',4,4'-tetrabromodiphenylether (TBDE) and 4,4'dibromodiphenylether (DBDE), as well as congeners of brominated bisphenol, such as 2,2',6,6'-tetrabromobisphenol A (TBBA), 2,2',6-tribromobisphenol (TriBBA) and 2,2'dibromobisphenol (DBBA). Likewise, we investigate congeners of 1,2-bis(2,4,6tribromophenoxy)ethane, including 1,2-bis(2,4,6-tribromophenoxy)ethane (BTBPE) itself, 1,2-bis(2,4-dibromophenoxy)ethane (BDBPE) and 1,2-bis(4-bromophenoxy)ethane (BMDPE), and study brominated congeners of cyclododecane comprising 1,2,5,6,9,10hexabromocyclododecane (HBCD), 1,2,5,6-tetrabromocyclododecane (TBCD) and 1,2dibromocyclododecane (DBCD). We capture the effect of bromine loading on the electronic and structural properties by contrasting the results for brominated species with their nonbrominated analogues. Investigated properties include energies of the lowest excited singlet states, oscillator strength, partial atomic charges and UV-Vis absorption spectra. We find it 
particularly important to report the properties of the first excited states of the studied BFRs in aqueous phase, as Sun et al. (2013) discovered the decomposition of PBDEs by visible light in the presence of carboxylate anions. We also elucidate a relationship between the thermal stability and photoreactivity of selected molecules, by studying the difference in energy between frontier molecular orbitals and the electronic charges. This energy difference constitutes prominent molecular descriptors of stability and photoreactivity of BFRs. Finally, we report experimentally measured UV-Vis spectra for TBBA and bisphenol A to benchmark the results of our theoretical calculations for their accuracy.

\section{Methods}

\subsection{Computational details}

Electronic structure calculations for selected brominated and non-brominated molecules of the flame retardant in the ground and excited states were executed using Accelrys' $\mathrm{DMol}^{3}$ (Delley, 2000) program. Geometry optimisation for all structures was performed using the DFT functional of GGA-PW91 (Perdew et al., 1992). The theoretical approach encompasses a double numerical basis set with $d$ polarisation function (DND) (1998) with an orbital cut-off radius of $4.4 \AA$ for numerical integration. The size of our numerical basis set is comparable to the Gaussian basis set of $6-31 \mathrm{G}^{*}$. Owing to the numerical optimisation, the DND basis set displays improved accuracy and holds small superposition errors than a size-equivalent Gaussian basis set (Delley, 1990). 
We deployed a conductor-like screening model (COSMO) to include the solvation effects in geometry optimisation (Klamt and Schüürmann, 1993; Klamt, 1995). All aqueous phase calculations involve relative permittivity of water of 78.5. We study the excited states of considered molecules by implementing the TDDFT approach (geometric convergence set to $10^{-6} \mathrm{Ha}$ ) along with the adiabatic local exchange density functional approximation (ALDA) (Zangwill and Soven, 1980). The UV-Vis absorption spectra were simulated using TDDFT calculations for the ground and excited state both in gaseous and aqueous phases (Delley, 2010). Eq. 1 illustrates the electronic transition from the initial $(i)$ to final $(f)$ states in the absorption process (Yao and Lin, 2008; Zhu et al., 2009; Wang et al., 2009):

$$
W_{i \rightarrow f}(\omega)=\frac{2 \pi}{h^{2}}\left|\mu_{f i .} E_{0}(\omega)\right|^{2} \sum_{v} \sum_{v^{\prime}} P_{i v}\left|\left(\Theta_{f v^{\prime}} \mid \Theta_{i v}\right)\right|^{2} D\left(\omega_{f v^{\prime}, i v}-\omega, \gamma_{f v^{\prime}, i v}\right)
$$

Whereas, Eq. 2 expresses the UV-Vis absorption spectrum:

$$
\alpha(\omega)=\frac{4 \pi^{2} \omega}{3 \hbar c a}\left|\mu_{f i}\right|^{2} \sum_{v} \sum_{v^{\prime}} P_{i v}\left|\left(\Theta_{f v^{\prime}} \mid \Theta_{i v}\right)\right|^{2} D\left(\omega_{f v^{\prime}, i v}-\omega, \gamma_{f v^{\prime}, i v}\right)
$$

In Eqs [1] and [2], $\mu_{f i}$ signifies the electronic transition dipole moment between the $i$ and $f$ states, $E_{0}$ denotes the amplitude of the vector for the incident sinusoidal electric field and $P_{i v}$ stands for the Boltzmann distribution factor. The expression $\left|\left(\Theta_{f v^{\prime}} \mid \Theta_{i v}\right)\right|$ characterises the Frank-Condon factor and $D\left(\omega_{f v^{\prime}, i v}-\omega, \gamma_{f v^{\prime}, i v}\right)$ denotes the Lorentzian-shape function with a damping factor $(\gamma)$. Furthermore, $v$ and $v^{\prime}$ are the vibrational quantum numbers corresponding to the electronic states $i$ and $f, c$ stands for the speed of light and $a$ expresses the solvation effect. 
We examined the atomic charges for the most photoreactive bromine atoms in BFR compounds based on the Hirshfeld population analysis (Delley, 1990). Hirshfeld methods constitute the most accurate computational formalism for the determination of atomic charges (Fonseca et al., 2004). The calculations of the optical properties of both gaseous and aqueous phases in the ground and excited state involved the optimised ground state molecular structures (Zhao and Han, 2009).

\subsection{Experimental}

We selected TBBA and bisphenol A for the experimental measurement of UV-Vis spectra. TBBA sample exists as a white solid powder purchased from Sigma Aldrich, Australia. Novachem, Australia (representative of Cambridge Isotope Laboratories, LGC, AccuStandard and Cerilliant) supplied a standard solution of bisphenol A in methanol. We acquired hexane and methanol solvents of GC grade (purity > 99.9\%) for the preparation of TBBA and bisphenol A solutions, respectively, from Chem Supply, Australia. The UV-Vis spectra of both samples were recorded in the region of $190 \mathrm{~nm}-800 \mathrm{~nm}$ on ultra violet-visible-near infrared spectrometer (Cary 5000 UV-Vis-NIR from Agilent Technologies) at $1 \mathrm{~nm}$ interval. The UVVis spectra of neat solvents served as the baseline corrections.

\section{Results and Discussion}

\subsection{Optimised structures in ground and excited states of selected BFRs}


Fig. 1 presents optimised geometries of the considered BFRs and their non-brominated counterparts, in the gaseous phase at the ground state $\left(\mathrm{S}_{0}\right)$, along with illustrative numbering of atoms and $\mathrm{C}-\mathrm{Br}$ bond lengths (in $\AA$ ). While HBCDs assume various energy-degenerate structural configurations, we elect to study properties of the $\delta$ isomer (Heeb et al., 2005). Table 1 lists prominent interatomic distances for $\mathrm{C}-\mathrm{Br}$ bonds in configurations arising in the gaseous and aqueous phases, for the $S_{0}$ and the first excited state $\left(S_{1}\right)$; refer to Fig. 1 for numbering of atoms. Contrasting the geometrical features in the $\mathrm{S}_{0}$ and $\mathrm{S}_{1}$ states provides valuable insight into trends governing the photodecomposition process as well as the effect of the degree of bromination on the photoreactivity of the title BFRs.

The structural parameters (particularly carbon-halogen bond lengths) of brominated compounds in the $S_{0}$ state differ from those in the $S_{1}$ state; both in the gaseous and aqueous phases. Upon excitation from the $\mathrm{S}_{0}$ to the $\mathrm{S}_{1}$ state, $\mathrm{C}-\mathrm{Br}$ bonds elongate, especially those at ortho position (Alaee et al., 2003; Li et al., 2007), leading us to make the following remarks:

(i) For brominated biphenyls, we observe the most extended elongation of the $\mathrm{C}-\mathrm{Br}$ bond at the ortho position with respect to the C-C bridge, i.e., $4.4 \%$ and $5.7 \%$ for HBB in gaseous and aqueous phases, respectively. Corresponding distances at the meta positions lengthened by $2.9 \%$ for $\mathrm{HBB}$ and $3.6 \%$ for DBB. Thus, the degree of elongation of $\mathrm{C}-\mathrm{Br}$ bond for $\mathrm{S}_{0} \rightarrow \mathrm{S}_{1}$ transitions follow the sequence of ortho>meta sites.

(ii) For PBDEs, the maximum lengthening of $\mathrm{C}-\mathrm{Br}$ bond occurs at the ortho position with regard to the $\mathrm{O}-\mathrm{C}$ bridge. For higher brominated congeners such as HBDE, the extent of $\mathrm{C}-\mathrm{Br}$ bond elongation exceeds that for the lower brominated species 
for the same position. For example, the ortho and meta $\mathrm{C}-\mathrm{Br}$ bond elongations in HBDE amount to $6.1 \%$ and $4.4 \%$, respectively. These percentages slightly overshoot the analogous values reported for DBDE at $5.3 \%$ and $4.1 \%$, correspondingly. Moreover, the presence of solvent media like water does not alter the position of the most elongated $\mathrm{C}-\mathrm{Br}$ bond. However, relative stretching (in \%, in reference to equilibrium distances in the $S_{0}$ state) reduces slightly for PBDEs in the aqueous medium.

(iii) In brominated congeners of bisphenol $\mathrm{A}$, one ortho $\mathrm{C}-\mathrm{Br}$ bond (with respect to the hydroxyl group), presents significant elongation of $8.8 \%$ and $9.0 \%$ for TBBA and TriBBA, respectively. The C-Br bonds in the other ortho positions stretch by 2.9 $\%-7.2 \%$, revealing the dependence of bond elongation on the position and degree of bromine substitution on the aromatic ring.

(iv) In BTBPE and BDBPE, the bromine substitution at the ortho position (with respect to the $\mathrm{C}-\mathrm{O}$ linkage) results in $7.1 \%$ and $4.5 \%$ lengthening of the $\mathrm{C}-\mathrm{Br}$ bond in the first excited state in the gaseous phase, in that order. The $\mathrm{C}$-Br bond stretching for BTBPE, BDBPE and BMBPE molecules at the meta position fall below these values, amounting to $4.4 \%, 4.0 \%$ and $1.8 \%$, respectively.

(v) The C-Br bonds in non-aromatic HBCD experience stretching upon the $\mathrm{S}_{0} \rightarrow \mathrm{S}_{1}$ transition, by $0.18 \AA ̊$ in gaseous and $0.17 \AA$ in aqueous media. Our computed C-Br bond lengths in the gaseous $\mathrm{S}_{0}$ state lie in the range of $2.023-2.044 \AA$ and are in reasonable agreement with other theoretically computed $\mathrm{C}$ - $\mathrm{Br}$ bond lengths for gaseous systems (i.e., $1.991-2.020 \AA$ ) (Zhao et al., 2010). 
(vi) The extent of elongation (as a percentage and an absolute value) of $\mathrm{C}$-Br bonds displays inconsistent variations in gaseous and aqueous media. The extent of $\mathrm{C}-\mathrm{Br}$ bond stretching in PBBs, PBDEs, BTBPEs and PBCDs in $\mathrm{S}_{0} \rightarrow \mathrm{S}_{1}$ transitions in gaseous phase exceed that in aqueous medium. However, for $\mathrm{S}_{0} \rightarrow \mathrm{S}_{1}$ shift, the percentage elongation of $\mathrm{C}-\mathrm{Br}$ bonds in brominated congeners of bisphenol $\mathrm{A}$ in aqueous phase surpasses the analogous extensions in the gaseous phase. For example, the ortho $\mathrm{C}-\mathrm{Br}$ (with respect to $\mathrm{C}-\mathrm{O}$ linkage) in BTBPE in the gaseous phase elongates by $0.109 \AA(5.6 \%)$ in comparison with $0.074 \AA(3.8 \%)$ in the aqueous medium. However, in TriBBA, the ortho $\mathrm{C}-\mathrm{Br}$ (with respect to $\mathrm{O}-\mathrm{H}$ bridge) elongates by $0.157 \AA(8.02 \%)$ in aqueous phase; slightly higher than the analogous elongation in the gaseous phase, reported as $0.139 \AA$ ( $7.2 \%)$. Therefore, we deduce that, the relative tendency of debromination of BFRs in the gaseous vs aqueous medium rests on the structure of the BFRs.

(vii) No significant variation in the geometries appears when exciting the nonbrominated species from the $S_{0}$ to the $S_{1}$ states in both media. This finding concurs with the general consensus in literature; i.e., brominated compounds appear more susceptible to photodecomposition than their non-substituted counterparts (Wang et al., 2012; Cruz et al., 2004; Eriksson et al., 2001a). Additionally, Table 1 indicates that, the presence of an aqueous medium does not induces any effect on the geometrical parameters of non-halogenated compounds.

Overall, values in Table 1 clearly establish the anticipated $\mathrm{C}-\mathrm{Br}$ bond elongation induced by the $\mathrm{S}_{0} \rightarrow \mathrm{S}_{1}$ transition; i.e., the rate-determining step in the photodecomposition process of 
BFRs (Zeng, 2007). The removal of the weakened $\mathrm{Br}$ atom (i.e., the atom associated with the highest photoreactivity) upon photodecomposition paves the way for the subsequent hydrogenation (formation of lower brominated congeners) observed experimentally (Fang et al., 2008; Christiansson et al., 2009; Mas et al., 2008). We report that, in all brominated compounds, the degree of elongation for $\mathrm{C}-\mathrm{Br}$ bond follows the sequence of ortho $>$ meta $>$ para positions. The aromatic compounds that entail a higher degree of bromination experience more $\mathrm{C}-\mathrm{Br}$ bond elongation in their first excited state for both gaseous and aqueous media. In other words, the lower-brominated congeners demonstrate less $\mathrm{C}$-Br bond stretching in comparison to the higher brominated congeners. Consequently, higher brominated congeners undergo reductive debromination more readily than the lower brominated isomers, in accord with the experimental results of Fang et al (2008).

\subsection{Frontier molecular orbitals and the HUMO-LUMO energy gap}

The difference in energy $\left(E^{\mathrm{H}-\mathrm{L}}\right)$ between the highest occupied molecular orbital (HOMO) and the lowest unoccupied molecular orbital (LUMO) constitutes an illuminating molecular descriptor of the photoreactivity of molecules (Klán and Wirz, 2009; Zhao and Han, 2009). The $E^{\mathrm{H}-\mathrm{L}}$ values dictate the movement of an electron from HOMO to LUMO during the $\mathrm{S}_{0} \rightarrow$ S $_{1}$ shift (Fang et al., 2008; Zhao and Han 2009). Fang et al., (2009) established a negative correlation between the energy gap, $E^{\mathrm{H}-\mathrm{L}}$, and the photolytic reactivity, $\log k$, for PBDE congeners in various media, including gaseous phase and hexane solvent. The decrease of the $E^{\mathrm{H}-\mathrm{L}}$ correlates linearly with the increase in the photoreactivity. 
Figs. S1 and S2 in the supplementary information depict HOMO and LUMO orbitals for all considered molecules, both in gaseous and aqueous media. Inspection of Fig. S1 reveals molecular fragments involved in the excitation process. The transitions from HOMO to LUMO for all aromatic compounds generally display $\pi \rightarrow \pi^{*}$ or $\pi \rightarrow \sigma^{*}$ character. The charge density in the HOMO of the departure state distributes itself over the entire aromatic rings, except for the photoexcitation of brominated congeners of cyclododecane that promotes the $n$ electrons. Conversely, the LUMO of the arrival state features either $\pi^{*}$ or $\sigma^{*}$ character. In the molecules of brominated congeners of biphenyls, diphenylethers, non-brominated biphenyls and diphenyl ether, BMBPE, TBBA, DBBA and bisphenol A, the HOMO and LUMO orbitals are of $\pi \rightarrow$ $\pi^{*}$ character, with the charge density of the LUMOs spreading itself over the entire aromatic rings.

Fig. S1 portrays the HOMO-LUMO transitions for TriBBA, BTBPE, BDBPE and cyclododecane molecules that display $\pi \rightarrow \sigma^{*}$ character. For brominated cyclododecane this transition involves promotion of electrons from $n$ to $\sigma^{*}$ orbitals. The LUMO rests on either the entire molecule (cyclododecane), on one phenyl group (TriBBA, BTBPE and BDBPE), or on a part of molecule (HBCD, TBCD and DBCD). Our calculated HOMO-LUMO orbital transitions for the molecular fragments of DBDE congeners accord with other TDDFT studies (Zhao et al., 2008; Wang et al., 2012; Pan and Bian, 2013).

Fig. 2 presents a linear negative correlation between the number of bromine substituents and $E^{\mathrm{H}-\mathrm{L}}$ for the considered BFRs and their non-brominated congeners for both gaseous and aqueous media. Calculated $E^{\mathrm{H}-\mathrm{L}}$ values fall in a range of $1.86-4.95 \mathrm{eV}$ for gaseous and aqueous configurations, except for those of cyclododecanes that peak around $8.06 \mathrm{eV}$. The non-aromatic structure of cyclododecane rationalises the noticeable difference in the $E^{\mathrm{H}-\mathrm{L}}$ 
values (Rai et al., 2007; Kornilovich et al., 2003). Bromine substitution in HBCD significantly reduces the $E^{\mathrm{H}-\mathrm{L}}$ value to $4.44 \mathrm{eV}$ and $4.49 \mathrm{eV}$ in gaseous and aqueous media, respectively, in reference to the non-brominated cyclododecane, i.e., $8.06 \mathrm{eV}$ (in gaseous phase) and $8.09 \mathrm{eV}$ (in aqueous medium). It follows that, two factors contribute to the high value of $E^{\mathrm{H}-\mathrm{L}}$ for cyclododecane: its non-aromatic structure and the absence of bromine substituents.

In the case of PBDEs, the $E^{\mathrm{H}-\mathrm{L}}$ amounts to $2.69 \mathrm{eV}$ for diphenylether substituted with 6 bromine atoms increasing to $3.74 \mathrm{eV}$ for DBDE. Additionally, the values of the energy gap for all brominated species fall below those of their non-brominated homologues, in both media. The HBB displays the lowest values of $E^{\mathrm{H}-\mathrm{L}}$ of $1.86 \mathrm{eV}$ and $1.48 \mathrm{eV}$ in gaseous and aqueous media, respectively. These values are significantly lower than those for non-halogenated biphenyls, i.e., $3.39 \mathrm{eV}$ (in gaseous phase) and $3.41 \mathrm{eV}$ (in aqueous phase). This finding concurs with the consensus in literature that, the photoreactivity correlates positively with the degree of bromination. Furthermore, the energy gap exhibits a negative linear relationship with the degree of bromination within each group of congeners (Wang et al., 2012; Saeed et al., 2015). Thus, we conclude that, higher brominated congeners demonstrate increased susceptibility towards photodecomposition owing to the lower $E^{\mathrm{H}-\mathrm{L}}$ values. Our $E^{\mathrm{H}-\mathrm{L}}$ energy analysis coincides with the theoretical predictions of $E^{\mathrm{H}-\mathrm{L}}$ for PBDE congeners (Wang et al., 2012; Luo et al., 2015). Overall, the medium (gaseous phase versus water solvent) induces a minor influence on the $E^{\mathrm{H}-\mathrm{L}}$ energies, in accord with previous theoretical findings on HBCDs of Zhao et al. (2010) and PBDEs of Wang et al. (2012). 


\subsection{Charge distribution}

We computed the partitioning of electronic density in considered brominated and nonbrominated compounds based on the Hirshfeld partitioning formalism (Hirshfeld, 1977; Wiberg and Rablen, 1993). This formalism provides a robust methodology for estimating atomic charges that is insensitive to the deployed basis set, in comparison with the commonly deployed Mulliken population analysis (Guerra et al., 2004; Davidson and Chakravorty, 1992). Table 2 depicts atomic charges on selected positions in all title compounds for the $\mathrm{S}_{0}$ gaseous state while Fig. S3 draws atomic charge contours for selected molecules. Charges on the bromine atoms $\left(q_{\mathrm{Br}}\right)$ substituted at different positions in molecule provide a measure of the extent of photoreactivity at ortho, meta and para sites with regard to the $\mathrm{C}-\mathrm{C} / \mathrm{C}-\mathrm{O}$ linkages and the $\mathrm{OH}$ group. The higher the charge on bromine atom $\left(q_{\mathrm{Br}}\right)$, the more propensity for the $\mathrm{Br}$ atom to depart the molecule via photodecomposition (Fang et al., 2009; Xie et al., 2009; Wang et al., 2012). The most photoreactive bromine atom holds the most positive charge in the gaseous ground state.

The results of charge analysis agree with the data of the earlier theoretical investigations (Eriksson et al., 2004; Wang et al., 2012). The carbon atoms attached to bromine atoms are richer in electrons, therefore, carrying a negative charge. Fig. 3 displays a positive correlation between the atomic charges of $\mathrm{Br}$ atom $\left(q_{\mathrm{Br}}\right)$ in the $\mathrm{S}_{0}$ state and elongation of $\mathrm{C}$ - $\mathrm{Br}$ bond lengths in the $S_{1}$ state for selected compounds, in both media. We find that, the bromine atom with the highest positive charge in the ground state experiences the maximum elongation in $\mathrm{C}$-Br bond length upon excitation; i.e., for the $\mathrm{S}_{0} \rightarrow \mathrm{S}_{1}$ transition. For example, in $\mathrm{S}_{0}$ state of the TBDE and BTBPE molecules, the bromine atom at ortho positions (with respect to C-O linkage) endures the highest positive charge of $0.086 e$ and $0.089 e$, correspondingly (refer to Table 2) 
and hence the longest $\mathrm{C}-\mathrm{Br}$ elongation upon excitation (in the $\mathrm{S}_{1}$ state). Similarly, in ground state of the TriBBA molecule, bromine atoms substituted at the ortho- $\mathrm{C}(\mathrm{Br})$ positions (with respect to the hydroxyl group) bear the utmost positive atomic charge of $0.076 e$ (most photoreactive $\mathrm{Br}$ atoms) and displays the maximum elongation in $\mathrm{C}-\mathrm{Br}$ bond of $9.0 \%$ in the first excited state. Overall, the photoreactivity of compounds increases with the degree of bromination, driven by a descending trend in $E^{\mathrm{H}-\mathrm{L}}$ energy gap and larger $q_{\mathrm{Br}}$ values.

\subsection{Optical properties including UV-Vis absorption spectra, excitation energies and oscillation strengths}

Molecules absorb the light photons in a discrete bundle of electromagnetic radiation (e.g., as sunlight). The energy of photons corresponding to visible or ultraviolet light is adequate to disrupt or rearrange the covalent bond, accelerate the photochemical process and generate the transient excited states that transform reactants into distinct products (Becker, 1971; Jackson, 1991). Photocatalysts shift the absorption of light from the UV region to the visible-light region, allowing more photons to be absorbed to induce the photochemical reactions. For this reason, in this contribution, we compute the photochemical properties such as excitation energies, oscillation strength and UV-Vis absorption spectra of the selected BFRs and their non-brominated counterparts. To establish an accuracy benchmark of theoretically obtained quantitates, we measure experimentally the UV-Vis spectra of TBBA in hexane and bisphenol A in methanol. This allows us to compare the maximum absorption wavelengths collected in the experiments in the UV-Vis range with those corresponding the highest oscillator strengths, as estimated in the computations. 
Tables 3 and 4 present the results of calculated excitation energies (in eV) and oscillator strengths $(f)$ for the five lowest excited states of selected brominated and non-brominated molecules in the gaseous and aqueous phase, respectively. Oscillator strength represents the probability of a chemical moiety to absorb or emit electromagnetic radiations to trigger electron transitions between two energy levels. Our computed results illustrate minor differences in excitation energies and oscillator strengths for all brominated and non-brominated congeners, in gaseous and aqueous media. The electron transition probabilities for $\mathrm{S}_{0} \rightarrow \mathrm{S}_{3}$ energy levels for DBB, HBB, DBDE, HBDE, bisphenol A, TriBBA, BTBPE, TBCD and HBCD appear much higher in comparison to the other energy transitions. Similarly, based on the values of oscillator strength, $\mathrm{S}_{0} \rightarrow \mathrm{S}_{2}$ represents the most accessible transition in biphenyl, $\mathrm{S}_{0} \rightarrow \mathrm{S}_{5}$ in TBDE, diphenylether, DBBA, bisphenoxyethane and BMBPE, and $\mathrm{S}_{0} \rightarrow \mathrm{S}_{4}$ in TBBA and DBCD.

Fig. 4 plots the excitation energy against the $E^{\mathrm{H}-\mathrm{L}}$ energy gap. In the case of non-brominated biphenyl, the excitation energy attains a value $4.16 \mathrm{eV}$ (with $E^{\mathrm{H}-\mathrm{L}}$ at $3.39 \mathrm{eV}$ ). This value surpasses considerably that associated with $\mathrm{HBB}$ of $2.35 \mathrm{eV}$ (with $E^{\mathrm{H}-\mathrm{L}}$ at $1.86 \mathrm{eV}$ ). For $\mathrm{HBCD}$, the required excitation energy amounts to $5.12 \mathrm{eV}$ (with $E^{\mathrm{H}-\mathrm{L}}$ at $4.44 \mathrm{eV}$ ); i.e., significantly lower in contrast to cyclododecane that necessitates the excitation energy of $8.12 \mathrm{eV}$ (with $E^{\mathrm{H}-}$ ${ }^{\mathrm{L}}$ at $8.06 \mathrm{eV}$ ). Thus, we conclude that, with the increase in the number of bromine substituents, the excitation energy decreases as function of the $E^{\mathrm{H}-\mathrm{L}}$ energy gap. Fig. 5a depicts the negative correlation between the number of bromine atoms and the excitation energy in agreement with the trend portrayed in Fig. 2 (between $E^{\mathrm{H}-\mathrm{L}}$ and the number of bromine atoms). In an analogy to this finding, our recent theoretical investigation on bromophenols (Saeed et al., 2015) predicted that, bromophenol congeners with the lowest excitation energy are those with the minimum $E^{\mathrm{H}-\mathrm{L}}$ values and the highest number of bromine substituents. 
The absorption of electromagnetic waves depends on the oscillator strength (Cantle, 1986), and hence we can compare these two quantities directly. Figs. 6 and 7 show the UV-Vis absorption spectra for all selected brominated and non-brominated compounds in the two media. Our calculated UV-Vis absorption spectrum of DBDE agrees well with the analogous experimental absorption spectrum (Marsh et al., 1999; Fang et al., 2009). Oscillator strength for all brominated and non-brominated molecules falls in a region of UV radiations, i.e., $150-530$ $\mathrm{nm}$ wavelength for both media. The optical spectra exhibit similar shapes in both gaseous and aqueous media for most compounds except for DBB, HBB and DBDE. These compounds display two intensive absorbance bands in aqueous phase, but only one in the gaseous phase. For example, for DBB, we observe one intense peak at a wavelength near $300 \mathrm{~nm}$ in the gaseous phase and two peaks in the aqueous phase at wavelengths of $240 \mathrm{~nm}$ and $300 \mathrm{~nm}$. Nevertheless, for brominated compounds in the aqueous phase, the band of oscillator strength exhibits a slight blue shift (shifts towards the region of shorter wavelength) in contrast to the gaseous phase. For instance, the strongest band for a gaseous phase HBB occurs at a wavelength of $528 \mathrm{~nm}$, reduced by $25 \mathrm{~nm}$ in the aqueous phase. Furthermore, we observe that, brominated compounds demonstrate low excitation energies and intense bands of oscillator strengths at longer wavelengths in contrast to non-brominated molecules.

Fig. 8 compares the experimental measurements of the maximum absorbance of UV-Vis radiation $\left(\lambda_{\max }\right)$ with the maximum oscillator strength, as obtained from computations. For a TBBA solution in hexane, the value of theoretically estimated $\lambda_{\max }$ of $293 \mathrm{~nm}$ falls close to the experimentally measured value of $\lambda_{\max }$ of $292 \mathrm{~nm}$. Similarly, bisphenol A in methanol exhibits the highest absorption peak at $283 \mathrm{~nm}$ in accord with the experimentally-observed estimate of $279 \mathrm{~nm}$. It follows that, the theoretically computed spectrum of oscillator strengths reasonably 
match the experimentally measured the absorbance spectrum, especially in terms of the location of the maximum peaks. However, it must be noted that, the calculated wavelength domain is somehow more extended in reference to experimental values. A similar discrepancy between computed and experimental shape of UV-Vis spectra has also been observed by Deblonde et al. (2015) who contrasted experimental and calculated spectra for hexaniobate and hexatantalate ions. The computational cost associated with the size of the investigated BFRs has prevented us from calculating the UV-Vis spectra at higher level of theory. Nonetheless, values computed herein using the $\mathrm{DMol}^{3}$ package were shown to largely reflect the position of the maximum peaks.

Now, we turn our attention to explain the effect of degree of bromination on the photolytic properties of the studied molecules. Fig. 5 portrays the relationship between the number of bromine atoms and the peak wavelength of the absorption bands. The figure discloses that, as the degree of bromination increases, the highest absorption peaks shift towards the region of longer wavelength for both gaseous and aqueous media, except for DBB. For example, nonbrominated biphenyl and HBB display absorption bands at wavelengths of $290 \mathrm{~nm}$ and 528 $\mathrm{nm}$, respectively. Likewise, HBCD exhibits an intense absorption peak at a wavelength of 276 $\mathrm{nm}$ that shifts towards shorter wavelengths by $42 \mathrm{~nm}, 56 \mathrm{~nm}$ and $130 \mathrm{~nm}$ for TBCD, DBCD and cyclododecane molecules, respectively, in the gaseous phase. Accordingly, we conclude that, bromine atoms attached to a molecule play a potent role in altering the photoreactivity of that molecule, by inducing a red shift in the maximum UV absorbance. Analogously, as the number of bromine atoms on the aromatic rings increases, so does the degree of red shift. For instance, six bromine atoms attached to a molecule (HBDE and BTBPE) induce a red shift of $65 \mathrm{~nm}$ and $92 \mathrm{~nm}$, respectively, in comparison to two dibrominated molecules (DBDE and BDBPE), as illustrated in Fig. 6. We observe a similar correlation between the red shift in the 
absorption peaks and the number of bromine substituents in the aqueous phase. However, the bromination of gaseous molecules induces a more profound red shift. The number of bromine substituents correlates positively with the computed wavelength of maximum absorbance. This observation agrees with the experimental results on the photodecomposition of PBDEs (Eriksson et al., 2004).

A careful examination of the absorption spectra for non-brominated compounds in both gaseous and aqueous media indicates that, in the absence of halogen atom in aromatic compounds, the absorption bands do not exhibit any shift when switching from gaseous to aqueous media. For example; biphenyl molecule unveils three absorption peaks with maximum intensity obtained at $191 \mathrm{~nm}, 242 \mathrm{~nm}$ and $290 \mathrm{~nm}$ in both aqueous and gaseous mediums.

\section{Conclusion}

The results of the present study indicate correlations between geometric and electronic properties that reflect the photoreactive nature of halogenated aromatic molecules. Compounds with the highest degree of bromination entail the lowest values of $E^{\mathrm{H}-\mathrm{L}}$ that necessitate the lowest excitation energies for state transitions, exhibiting red shifts for the position of the maximum absorption peaks in the UV-Vis spectra. Our experimentally measured maxima in $\mathrm{UV}$-Vis spectra concur with the location of the theoretically computed wavelengths of the oscillator strengths. Bromine atoms attached to ortho- $\mathrm{C}$ (with respect to $\mathrm{C}-\mathrm{C}$ and $\mathrm{C}-\mathrm{O}$ linkages or the hydroxyl groups) hold the highest positive atomic charges and thus experience the most significant lengthening of the $\mathrm{C}-\mathrm{Br}$ bonds in their first excited states, in both media, prompting 
their preferential debromination. On the other hand, the analogous non-brominated aromatic hydrocarbons possess the highest $E^{\mathrm{H}-\mathrm{L}}$ excitation energies and display maximum absorption peaks at shorter wavelengths, indicating their relative stability against photodecomposition.

The computed values of $E^{\mathrm{H}-\mathrm{L}}$ for selected BFRs and their non-brominated congeners reveal that, the number of bromine substituents and the nature of molecular structure (especially, present of lack of aromaticity) significantly affects the photoreactivity of molecules.

Conflict of interest: The authors declare that they have no conflict of interest.

\section{Acknowledgments}

This study has been supported by the Australian Research Council (ARC), and grants of computing time from the National Computational Infrastructure (NCI), Australia as well as the Pawsey Supercomputing Centre in Perth. A.S. and K.S. thank Murdoch University for the postgraduate research scholarships. 


\section{References}

Alaee, M., Arias, P., Sjödin, A., Bergman, Å., 2003. An overview of commercially used brominated flame retardants, their applications, their use patterns in different countries/regions and possible modes of release. Environ. Int. 29, 683-689.

Ali, N., Harrad, S., Goosey, E., Neels, H., Covaci, A., 2011a. "Novel" brominated flame retardants in Belgian and UK indoor dust: Implications for human exposure. Chemosphere 83, $1360-1365$.

Ali, N., Harrad, S., Muenhor, D., Neels, H., Covaci, A., 2011b. Analytical characteristics and determination of major novel brominated flame retardants (NBFRs) in indoor dust. Anal. Bioanal. Chem. 400, 3073-3083.

Altarawneh, M., Dlugogorski, B.Z., 2013. A mechanistic and kinetic study on the formation of PBDD/Fs from PBDEs. Environ. Sci. Technol. 47, 5118-5127.

Altarawneh, M., Dlugogorski, B.Z., 2014a. Thermal decomposition of 1,2-bis(2,4,6tribromophenoxy)ethane (BTBPE), a novel brominated flame retardant. Environ. Sci. Technol. $48,14335-14343$.

Altarawneh, M., Dlugogorski, B.Z., 2014b. Mechanism of thermal decomposition of tetrabromobisphenol A (TBBA). J. Phys. Chem. A. 118, 9338-9346.

Altarawneh, M., Dlugogorski, B.Z., 2015. Formation of polybrominated dibenzofurans from polybrominated biphenyls. Chemosphere 119, 1048-1053.

Barontini, F., Cozzani, V., Marsanich, K., Raffa, V., Petarca, L., 2004. An experimental investigation of tetrabromobisphenol A decomposition pathways. J. Anal. Appl. Pyrolysis. 72, 41-53. 
Barontini, F., Cozzani, V., 2006. Formation of hydrogen bromide and organobrominated compounds in the thermal degradation of electronic boards. J. Anal. Appl. Pyrolysis. 77, 4155.

Becker, R.S., 1971. Photochemical process. U.S. Pat. 3,567,605.

Buser, H.R., 1986. Polybrominated dibenzofurans and dibenzo- $p$-dioxins: thermal reaction products of polybrominated diphenyl ether flame retardants. Environ. Sci. Technol. 20, 404408.

Cantle, J. E., 1986. Atomic Absorption Spectyrometry. Elsevier Science, Vol 5.

Chatterjee, D., Dasgupta, S., 2005. Visible light induced photocatalytic degradation of organic pollutants. J. Photochem. Photobiol. C: Photochem. Rev 6, 186-205.

Choi, K.-I., Lee, S.-H., Osako, M., 2009. Leaching of brominated flame retardants from TV housing plastics in the presence of dissolved humic matter. Chemosphere 74, 460-466.

Christiansson, A., Eriksson, J., Teclechiel, D., Bergman, Å., 2009. Identification and quantification of products formed via photolysis of decabromodiphenyl ether. Environ. Sci. Pollut. Res. 16, 312-321.

Covaci, A., Voorspoels, S., de Boer, J., 2003. Determination of brominated flame retardants, with emphasis on polybrominated diphenyl ethers (PBDEs) in environmental and human samples-a review. Environ. Int. 29, 735-756.

Covaci, A., Harrad, S., Abdullah, M. A.E., Ali, N., Law, J. R., Herzke, D., de Wit, C. A., 2011. Novel brominated flame retardants: A review of their analysis, environmental fate and behaviour. Environ. Int. 37, 532-556.

Cruz, J.B., Jafvert, C. T., Hua, I., 2004. Solar photodecomposition of decabromodiphenyl ether: products and quantum yield. Environ. Sci. Technol. 38, 4149-4156. 
Darnerud, P.O., 2003. Toxic effects of brominated flame retardants in man and in wildlife. Environ. Int. 29, 841-853.

Davidson, E.R., Chakravorty, S., 1992. A test of the Hirshfeld definition of atomic charges and moments. Anal. Chim. Acta. 83, 319-330.

Deblonde, J.-P.G., Moncomble, A., Cote, G., Bélair, S., Chagnes, A., 2015. Experimental and computational exploration of the UV-visible properties of hexaniobate and hexatantalate ions. RSC Adv., 5, 7619-7627.

de Wit, C.A., 2002. An overview of brominated flame retardants in the environment. Chemosphere 46, 583-624.

Delley, B., 1990. An all-electron numerical method for solving the local density functional for polyatomic molecules. J. Chem. Phys. 92, 508-517.

Delley, B., 2000. From molecules to solids with the DMol ${ }^{3}$ approach. J. Chem. Phys. 113, 7756-7764.

Delley, B., 2010. Time dependent density functional theory with DMol ${ }^{3}$. J. Phys.: Condens. Matter. 22, 384208.

Eguchia, A., Isobea, T., Ramua, K., Tuea, N. M., Sudaryantoa, A., Devanathana, G., Vietd, P.H., Tanae, R.S., Takahashia, S., Subramaniana, A., Tanabea, S., 2013. Soil contamination by brominated flame retardants in open waste dumping sites in Asian developing countries. Chemsophere 90, 2365-2371.

Eljarrat, E., de la Cal, A., Raldua, D., Duran, C., Barcelo, D., 2005. Brominated flame retardants in Alburnus from Cinca River Basin (Spain). Environ. Pollut. 133, 501-508.

Eriksson, J., Jakobsson, E., Marsh, G., Bergman, A., 2001a. Photodecomposition of brominated diphenylethers in methanol/water [Abstract]. Presented at the Second International Workshop on Brominated Flame Retardants, 14-16 May,Stockholm, Sweden. 
Eriksson, J., Eriksson, L., 2001. 2,2',6,6'-Tetrachloro-4,4'-propane-2,2-diyldiphenol, 2,2',6tribromo-4,4'-propane-2,2-diyldiphenol and 2,2',6,6'-tetrabromo-4,4'-propane-2,2diyldiphenol. Acta Crystallogr. C 57, 1308-1312.

Eriksson, J., Green, N., Marsh, G., Bergman, Å., 2004. Photochemical decomposition of 15 polybrominated diphenyl ether congeners in methanol/water. Environ. Sci. Technol. 38, 31193125 .

Eriksson, P., Jakobsson, E., Fredriksson, A., 2001. Brominated flame retardants: a novel class of developmental neurotoxicants in our environment? Environ Health Perspect. 109, 903-908.

Fang, L., Huang, J., Yu, G., Li, X., 2009. Quantitative structure-property relationship studies for direct photolysis rate constants and quantum yields of polybrominated diphenyl ethers in hexane and methanol. Ecotoxicol. Environ. Saf. 72, 1587-1593.

Fang, L., Huang, J., Yu, G., Wang, L., 2008. Photochemical degradation of six polybrominated diphenyl ether congeners under ultraviolet irradiation in hexane. Chemosphere 71, 258-267.

Fonseca, C. G., Handgraaf, J.W., Baerends, E.J., Bickelhaupt, F.M. 2004. Voronoi deformation density (VDD) charges: Assessment of the Mulliken, Bader, Hirshfeld, Weinhold, and VDD methods for charge analysis. J. Comput. Chem 25, 189-210.

Fromme, H., Hilger, B., Kopp, M., Völkel, W.M., 2014. Polybrominated diphenyl ethers (PBDEs), hexabromocyclododecane (HBCD) and "novel" brominated flame retardants in house dust in Germany. Environ. Int. 64, 61-68.

Guerra, F. C., Handgraaf, J.W., Baerends, E.J., Bickelhaupt, F.M., 2004. Voronoi deformation density (VDD) charges: assessment of the mulliken, bader, hirshfeld, weinhold, and VDD methods for charge analysis. J. Comput. Chem. 25, 189-210. 
Gullett, B.K., Linak, W.P., Touati, A., Wasson, S.J., Gatica, S., King. C.J., 2007. Characterization of air emissions and residual ash from open burning of electronic wastes during simulated rudimentary recycling operations. J. Mater. Cycles Waste Manage. 9, 69-79.

Heeb, N.V., Schweizer, W. B., Kohler, M., Gerecke, A.C., 2005. Structure elucidation of hexabromocyclododecanes -a class of compounds with a complex stereochemistry. Chemosphere 61, 65-73.

Hirshfeld, F.L., 1977. Bonded-atom fragments for describing molecular charge densities. Theoretica chimica acta 44, 129-138.

Jackson, D.P., 1991. Dense phase gas photochemical process for substrate treatment. Google Patent.

Jaward, F.M., Farrar, N.J., Harner, T., Sweetman, A.J., Jones, K.C. 2004. Passive air sampling of PCBs, PBDEs, and organochlorine pesticides across Europe. Environ. Sci. Technol. 38, $34-41$.

Joschek, H.I., Miller, S.I., 1966. Photocleavage of phenoxyphenols and bromophenols. J. Am. Chem. Soc. 88, 3269-3272.

Klamt, A., 1995. Conductor-like screening model for real solvents: A new approach to the quantitative calculation of solvation phenomena. J. Phys. Chem. 99, 2224-2235.

Klamt, A., Schüürmann, G., 1993. COSMO: a new approach to dielectric screening in solvents with explicit expressions for the screening energy and its gradient. J. Chem. Soc. Perkin. Trans. 2, 799-805.

Kornilovich, P., Bratkovski, A.M., Chang, S.C., Williams, R.S., 2003. Low-forward-voltage molecular rectifier. U.S. Pat. 6670631 B2. 
Li, A., Tai, C., Zhao, Z., Wang, Y., Zhang, Q., Jiang, G., Hu, J., 2007. Debromination of decabrominated diphenyl ether by resin-bound iron nanoparticles. Environ. Sci. Technol. 41, 6841-6846.

Luijk, R., Govers, H.A.J., 1992. The formation of polybrominated dibenzo-p-dioxins (PBDDs) and dibenzofurans (PBDFs) during pyrolysis of polymer blends containing brominated flame retardants. Chemosphere 25, 361-374.

Luo, J., Hu, J., Wei, X., Li, L., Huang, X., 2015. Excited states and photodebromination of selected polybrominated diphenyl ethers: computational and quantitative structure -property relationship studies. Int. J. Mol. Sci. 16, 1160.

Luda, M.P., Balabanovich, A.I., Camino, G., 2002. Thermal decomposition of fire retardant brominated epoxy resins. J. Anal. Appl. Pyrolysis. 65, 25-40.

Marsh, G., Hu, J., Jakobsson, E., Rahm, S., Bergman, Ȧ., 1999. Synthesis and characterization of 32 polybrominated diphenyl ethers. Environ. Sci. Technol. 33, 3033-3037.

Mas, S., Juan, A. d., Lacorte, S., Tauler, R., 2008. Photodegradation study of decabromodiphenyl ether by UV spectrophotometry and a hybrid hard- and soft-modelling approach. Anal. Chim. Acta. 618,18-28.

Mimmoa, T., Hannb, S., Jaitzb, L., Cescoa, S., Gessac, C.E., Puschenreiterd, M., 2011. Time and substrate dependent exudation of carboxylates by Lupinus albus L. and Brassica napus L. Plant Physiol. Biochem. 49, 1272-1278.

Möller, A., Xie, Z., Sturm, R., Ebinghaus, R., 2011. Polybrominated diphenyl ethers (PBDEs) and alternative brominated flame retardants in air and seawater of the European Arctic. Environ. Pollut. 159, 1577-1583.

Morris, S., Allchin, C.R., Zegers, B.N., Haftka, J.J.H., Boon, J.P., Belpaire, C., Leonards, P.E.G., van Leeuwen, S.P.J., de Boer, J., 2004. Distribution and fate of HBCD and TBBPA brominated flame retardants in north sea estuaries and aquatic food webs. Environ. Sci. Technol. 38, 5497-5504. 
Norris, J.M., Ehrmantraut, J.W., Gibbons, C.L., Kociba, R.J., Schwetz, B.A., Rose, J.Q., Humiston, C.G., Jewett, G.L., Crummett, W.B., Gehring, P.J., Tirsell, J.B., Brosier, J.S., 1973. Toxicological and environmental factors involved in the selection of decabromodiphenyl oxide as a fire retardant chemical. Appl. Polym. Symp. 22, 195-219.

Otha, S., Nishimura, H., Nakao, T., Aozasa, O., Miyata, H., 2001. Characterization of the photolysis of Decabromodiphenyl ether and the levels of PBDEs as its photoproducts in atmospheric air of japan. Organohalogen Compd. 52, 321-324

Ortuño, N., Moltó, J., Conesa, J. A., Font, R., 2014. Formation of brominated pollutants during the pyrolysis and combustion of tetrabromobisphenol A at different temperatures. Environ. Pollut. 191, 31-37.

Pan, L., Bian, W., 2013. Theoretical study on the photodegradation mechanism of nona-BDEs in methanol. ChemPhysChem 14, 1264-1271.

Perdew, J.P., Chevary, J.A., Vosko, S.H., Jackson, K.A., Pederson, M.R., Singh, D.J., Fiolhais, C., 1992. Atoms, molecules, solids, and surfaces: Applications of the generalized gradient approximation for exchange and correlation. Phys. Rev. B. 46, 6671-6687.

Petr. K., Jakob.W., 2009. Photochemistry of Organic Compounds. From Concepts to Practice. John Wiley \& Sons.

Rai, D., Joshi, H., Kulkarni, A.D., Gejji, S.P., Pathak, R.K., 2007. Electric field effects on aromatic and aliphatic hydrocarbons: a density-functional study. J. Phys. Chem. A. 111, 91119121.

Saeed, A, Dlugogorski, B.Z., Altarawneh M., 2015. Formation of brominated and nonbrominated species from gas-phase thermal decomposition of pure TBBA. 14th International Congress on Combustion By-Products and Their Health Effects, Umeå, Sweden.

Saeed A., Altarawneh, M., Dlugogorski BZ., 2016a. Formation of PBDD/F precursors in gasphase decomposition of tetrabromobisphenol A (TBBA). Organohalogen Compd. 78, 672-674. 
Saeed, A., Altarawneh, M., Dlugogorski, B.Z., 2016b. Photodecomposition of bromophenols. Chemosphere 150, 749-758.

Sakai, S.-i., Watanabe, J., Honda, Y., Takatsuki, H., Aoki, I., Futamatsu, M., Shiozaki, K., 2001. Combustion of brominated flame retardants and behavior of its byproducts. Chemosphere 42, 519-531.

Sellström, U., Kierkegaard, A., Alsberg, T., Jonsson, P., Wahlberg, C., De Wit, C., 1999. Brominated flame retardants in sediments from europena estuaries, the Baltic Sea and in sewage sludge. Organohalogen Compd. 40, 383-386.

Söderström, G., Sellström, U., de Wit, C.A., Tysklind, M., 2004. Photolytic debromination of decabromodiphenyl ether (BDE 209). Environ. Sci. Technol. 38, 127-132.

Stapleton, H.M., Klosterhaus, S., Keller, A., Ferguson, P.L., Bergen, S.V., Coopert, E., Webster, T.F., Blum, A., 2011. Identification of flame retardants in polyurethane foam collected from baby products. Environ. Sci. Technol. 45, 5323-5331.

Suh, Y.W., Buettner, G.R., Venkataraman, S., Treimer, S.E., Robertson, L.W., Ludewig, G., 2009. UVA/B-induced formation of free radicals from decabromodiphenyl ether. Environ. Sci. Technol. 43, 2581-2588.

Sun, C., Chang, W., Ma, W., Chen, C., Zhao, J., 2013. Photoreductive debromination of decabromodiphenyl ethers in the presence of carboxylates under visible light irradiation. Environ. Sci. Technol. 47, 2370-2377.

Tian, M., Chen, S.J., Wang, J., Zheng, X.B., Luo, X.J., Mai, B,X., 2011. Brominated flame retardants in the atmosphere of e-waste and rural sites in southern china: seasonal variation, temperature dependence, and gas-particle partitioning. Environ. Sci. Technol. 45, 8819-8825.

Wang, S., Hao, C., Gao, Z., Chen, J., Qiu, J., 2012. Effects of excited-state structures and properties on photochemical degradation of polybrominated diphenyl ethers: A TDDFT study. Chemosphere 88, 33-38. 
Wang, H., Zhu, C., Yu, J.G., Lin, S. H. 2009. Anharmonic Franck-Condon simulation of the absorption and fluorescence spectra for the low-lying $S_{1}$ and $S_{2}$ excited states of pyridine. J. Phys. Chem. A. 113, 14407-14414.

Watanabe, I., Sakai, S.I., 2003. Environmental release and behavior of brominated flame retardants. Environ. Int. 29, 665-682.

Watanabe, I., Tatsukawa, R., 2008. Formation of brominated dibenzofurans from the photolysis of flame retardant decabromobiphenyl ether in hexane solution by UV and sun light. Bull. Environ. Contam. and Toxicol. 39, 953-959.

Weber, R., Kuch, B., 2003. Relevance of BFRs and thermal conditions on the formation pathways of brominated and brominated-chlorinated dibenzodioxins and dibenzofurans. Environ. Int. 29, 699-710.

Wiberg, K.B., Rablen, P.R., 1993. Comparison of atomic charges derived via different procedures. J. Comput. Chem. 14, 1504-1518.

Xie, Q., Chen, J., Shao, J., Chen, C.e., Zhao, H., Hao, C., 2009. Important role of reaction field in photodegradation of deca-bromodiphenyl ether: Theoretical and experimental investigations of solvent effects. Chemosphere 76, 1486-1490.

Yao, L., Lin, S.H. 2008. The anharmonic effect study of coupled morse oscillators for the unimolecular reaction. Sci. China, Ser. B, Chem. 51, 1146-1152.

Zangwill, A., Soven, P., 1980. Density-functional approach to local-field effects in finite systems: Photoabsorption in the rare gases. Phys. Rev. A 21, 1561-1572.

Zeng, X., 2007. Development, Validation and the Application of a Congener Specific Photodegradation Model for PBDEs. Oregon State University 
Zhao, G.-J., Han, K.L., 2009. Excited state electronic structures and photochemistry of heterocyclic annulated perylene (HAP) materials tuned by heteroatoms: $\mathrm{S}, \mathrm{Se}, \mathrm{N}, \mathrm{O}, \mathrm{C}, \mathrm{Si}$, and B. J. Phys. Chem. A, 113, 4788-4794.

Zhao, Y.Y., Tao, F.M., Zeng, E.Y., 2008. Theoretical study on the chemical properties of polybrominated diphenyl ethers. Chemosphere 70, 901-907.

Zhao, Y.Y., Zhang, X.H., Sojinu, O.S.S., 2010. Thermodynamics and photochemical properties of a, b, and c-hexabromocyclododecanes: A theoretical study. Chemosphere 80, 150156.

Zhu, C., Liang, K.K., Hayashi, M., Lin, S.H. 2009. Theoretical treatment of anharmonic effect on molecular absorption, fluorescence spectra, and electron transfer. J. Chem. Phys. 358, 137146. 


\section{Table 1}

Comparison of bond lengths $(\mathrm{C}-\mathrm{Br})$ for the title BFRs and their non-brominated congeners in the ground $\left(\mathrm{S}_{\mathrm{o}}\right)$ and excited $\left(\mathrm{S}_{1}\right)$ states in both gaseous and aqueous media. Bond lengths are in $\AA$. Atomic positions are shown in Fig. 1 .

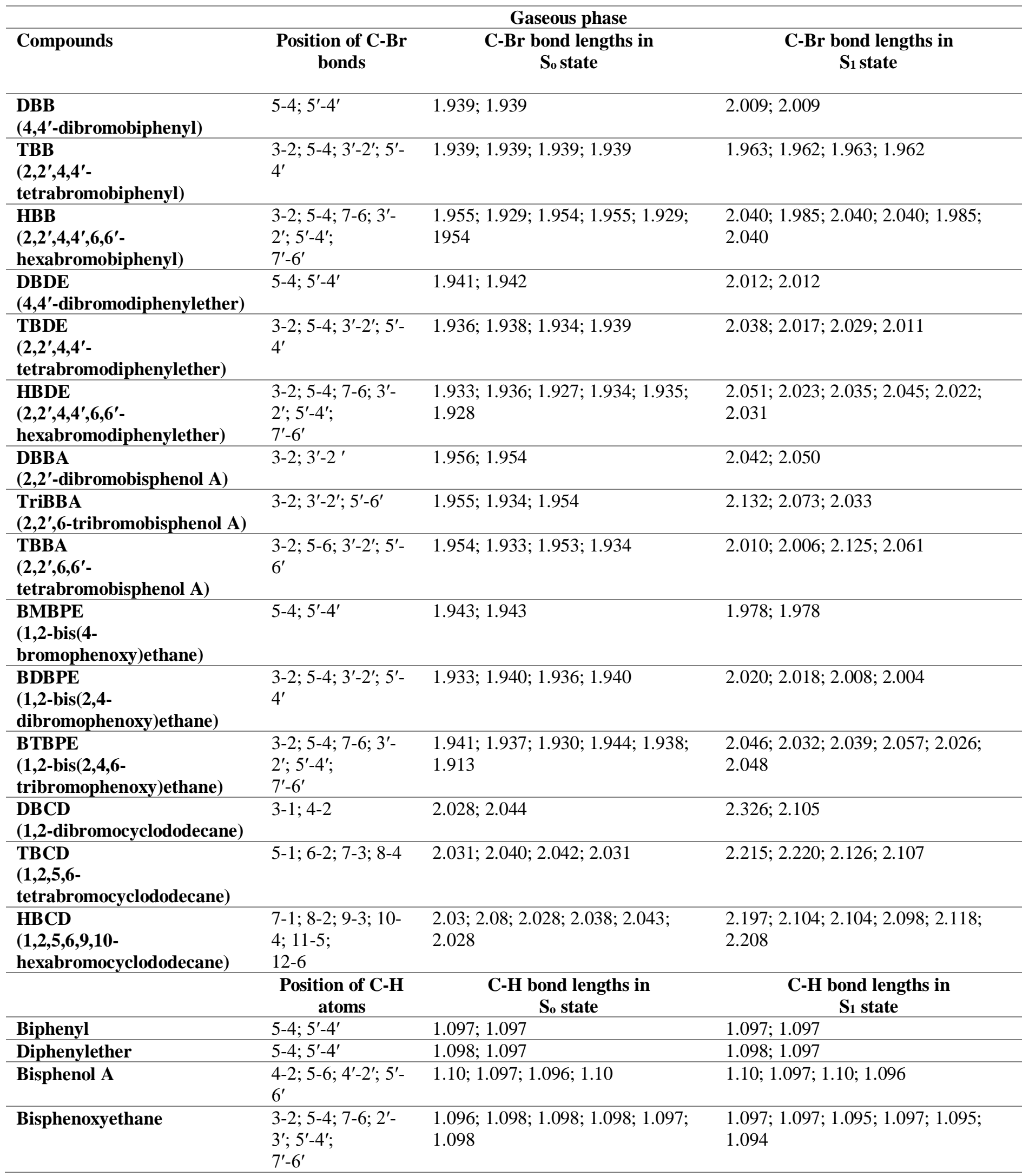




\begin{tabular}{|c|c|c|c|}
\hline Cyclododecane & $\begin{array}{l}7-1 ; 8-2 ; 9-3 ; 10- \\
4 ; 11-5 ; \\
12-6\end{array}$ & $\begin{array}{l}1.114 ; 1.115 ; 1.114 ; 1.115 ; 1.114 ; \\
1.115\end{array}$ & $\begin{array}{l}1.117 ; 1.115 ; 1.114 ; 1.115 ; 1.114 ; \\
1.115\end{array}$ \\
\hline \multicolumn{4}{|c|}{ Solvent phase (aqueous) } \\
\hline & $\begin{array}{c}\begin{array}{c}\text { Position of C-Br } \\
\text { atoms }\end{array} \\
\text { atom }\end{array}$ & $\begin{array}{l}\text { C-Br bond lengths in } \\
S_{0} \text { state }\end{array}$ & $\begin{array}{c}\text { C-Br bond lengths in } \\
S_{1} \text { state }\end{array}$ \\
\hline DBB & $5-4 ; 5^{\prime}-4^{\prime}$ & $1.948 ; 1.948$ & $2.007 ; 2.007$ \\
\hline TBB & $\begin{array}{l}3-2 ; 5-4 ; 3^{\prime}-2^{\prime} ; 5^{\prime}- \\
4^{\prime}\end{array}$ & $1.939 ; 1.936 ; 1.939 ; 1.936$ & $1.945 ; 1.944 ; 1.945 ; 1.944$ \\
\hline HBB & $\begin{array}{l}3-2 ; 5-4 ; 7-6 ; 3^{\prime}- \\
2^{\prime} ; 5^{\prime}-4^{\prime} ; \\
7^{\prime}-6^{\prime}\end{array}$ & $\begin{array}{l}1.941 ; 1.937 ; 1.939 ; 1.940 ; 1.936 ; \\
1.39\end{array}$ & $\begin{array}{l}2.050 ; 2.028 ; 2.050 ; 2.050 ; 2.028 \\
2.050\end{array}$ \\
\hline DBDE & $5-4 ; 5^{\prime}-4^{\prime}$ & $1.949 ; 1.950$ & $2.011 ; 2.010$ \\
\hline TBDE & $\begin{array}{l}3-2 ; 5-4 ; 3^{\prime}-2^{\prime} ; 5^{\prime}- \\
4^{\prime}\end{array}$ & $1.939 ; 1.944 ; 1.937 ; 1.944$ & $2.041 ; 2.020 ; 2.031 ; 2.015$ \\
\hline HBDE & $\begin{array}{l}3-2 ; 5-4 ; 7-6 ; 3^{\prime}- \\
2^{\prime} ; 5^{\prime}-4^{\prime} ; \\
7^{\prime}-6^{\prime}\end{array}$ & $\begin{array}{l}1.935 ; 1.931 ; 1.939 ; 1.935 ; 1.931 ; \\
1.938\end{array}$ & $\begin{array}{l}2.050 ; 2.022 ; 2.038 ; 2.050 ; 2.022 ; \\
2.038\end{array}$ \\
\hline DBBA & $3-2 ; 3^{\prime}-2^{\prime}$ & $1.955 ; 1.955$ & $2.042 ; 2.050$ \\
\hline TriBBA & $3-2 ; 3^{\prime}-2^{\prime} ; 5^{\prime}-6^{\prime}$ & $1.951 ; 1.943 ; 1.954$ & $2.131 ; 2.100 ; 2.035$ \\
\hline TBBA & $\begin{array}{l}3-2 ; 5-6 ; 3^{\prime}-2^{\prime} ; 5^{\prime}- \\
6^{\prime}\end{array}$ & $1.950 ; 1.942 ; 1.951 ; 1.942$ & $2.010 ; 2.006 ; 2.104 ; 2.057$ \\
\hline BMBPE & $5-4 ; 5^{\prime}-4^{\prime}$ & $1.952 ; 1.952$ & $1.978 ; 1.978$ \\
\hline BDBPE & $\begin{array}{l}3-2 ; 5-4 ; 3^{\prime}-2^{\prime} ; 5^{\prime}- \\
4^{\prime}\end{array}$ & $1.940 ; 1.946 ; 1.940 ; 1.947$ & $2.020 ; 2.018 ; 2.008 ; 2.004$ \\
\hline BTBPE & $\begin{array}{l}3-2 ; 5-4 ; 7-6 ; 3^{\prime}- \\
2^{\prime} ; 5^{\prime}-4^{\prime} ; \\
7^{\prime}-6^{\prime}\end{array}$ & $\begin{array}{l}1.936 ; 1.939 ; 1.939 ; 1.939 ; 1.939 ; \\
1.936\end{array}$ & $\begin{array}{l}2.020 ; 2.005 ; 2.013 ; 2.042 ; 2.033 ; \\
2.047\end{array}$ \\
\hline DBCD & $3-1 ; 4-2$ & $2.045 ; 2.064$ & $2.334 ; 2.125$ \\
\hline TBCD & $5-1 ; 6-2 ; 7-3 ; 8-4$ & $2.044 ; 2.056 ; 2.058 ; 2.047$ & $2.324 ; 2.340 ; 2.234 ; 2.207$ \\
\hline \multirow[t]{2}{*}{ HBCD } & $\begin{array}{l}7-1 ; 8-2 ; 9-3 ; 10- \\
4 ; 11-5 ; \\
12-6\end{array}$ & $\begin{array}{l}2.028 ; 2.031 ; 2.028 ; 2.043 ; 2.038 ; \\
2.028\end{array}$ & $\begin{array}{l}2.196 ; 2.100 ; 2.104 ; 2.009 ; 2.119 ; \\
2.207\end{array}$ \\
\hline & $\begin{array}{l}\text { Position of C-H } \\
\text { atoms }\end{array}$ & $\begin{array}{c}\mathrm{C}-\mathrm{H} \text { bond lengths in } \\
\mathrm{S}_{\mathrm{o}} \text { state }\end{array}$ & $\begin{array}{c}\mathrm{C}-\mathrm{H} \text { bond lengths in } \\
\mathrm{S}_{1} \text { state }\end{array}$ \\
\hline Biphenyl & $5-4 ; 5^{\prime}-4^{\prime}$ & $1.097 ; 1.097$ & $1.097 ; 1.097$ \\
\hline Diphenylether & $5-4 ; 5^{\prime}-4^{\prime}$ & $1.098 ; 1.097$ & $1.098 ; 1.097$ \\
\hline Phenol & $6-2 ; 7-3 ; 8-4 ; 9-5$ & $1.10 ; 1.098 ; 1.098 ; 1.098$ & $1.10 ; 1.098 ; 1.098 ; 1.099$ \\
\hline Bisphenol A & $\begin{array}{l}4-2 ; 5-6 ; 4^{\prime}-2^{\prime} ; 5^{\prime}- \\
6^{\prime}\end{array}$ & $1.10 ; 1.097 ; 1.096 ; 1.10$ & $1.10 ; 1.098 ; 1.097 ; 1.10$ \\
\hline Bisphenoxyethane & $\begin{array}{l}3-2 ; 5-4 ; 7-6 ; 2^{\prime}- \\
3^{\prime} ; 5^{\prime}-4^{\prime} ; \\
7^{\prime}-6^{\prime}\end{array}$ & $\begin{array}{l}1.096 ; 1.098 ; 1.098 ; 1.098 ; 1.097 ; \\
1.098\end{array}$ & $\begin{array}{l}1.099 ; 1.098 ; 1.101 ; 1.100 ; 1.098 ; \\
1.098\end{array}$ \\
\hline Cyclododecane & $\begin{array}{l}7-1 ; 8-2 ; 9-3 ; 10- \\
4 ; 11-5 ; \\
12-6\end{array}$ & $\begin{array}{l}1.114 ; 1.115 ; 1.114 ; 1.115 ; 1.114 ; \\
1.115\end{array}$ & $\begin{array}{l}1.114 ; 1.115 ; 1.114 ; 1.115 ; 1.114 ; \\
1.115\end{array}$ \\
\hline
\end{tabular}




\section{Table 2}

Atomic charges on the selected BFRs. The parameter $n$ represents the position of oxygen $(\mathrm{O})$, bromine $(\mathrm{Br})$ and carbon $(\mathrm{C})$ atoms with the value of net atomic charge present in the ground state $\left(\mathrm{S}_{\circ}\right)$ in the gaseous phase. Atomic positions are depicted in Fig. 1.

\begin{tabular}{|c|c|c|}
\hline Compounds & $n$ & $\begin{array}{l}\text { Atomic charges } \\
\qquad\left(\mathbf{S}_{0}\right)\end{array}$ \\
\hline DBB & $\mathrm{Br}(4) ; \mathrm{Br}\left(4^{\prime}\right) ; \mathrm{C}(5) ; \mathrm{C}\left(5^{\prime}\right)$ & $0.0725 ; 0.0725 ;-0.0293 ;-0.0294$ \\
\hline TBB & $\begin{array}{l}\mathrm{Br}(2) ; \operatorname{Br}\left(2^{\prime}\right) ; \operatorname{Br}(4) ; \operatorname{Br}\left(4^{\prime}\right) ; \mathrm{C}(3) ; \\
\mathrm{C}\left(3^{\prime}\right) ; \mathrm{C}(5) ; \mathrm{C}\left(5^{\prime}\right)\end{array}$ & $\begin{array}{l}0.0802 ; 0.0802 ; 0.0721 ; 0.0721 ;- \\
0.0323 ;-0.0322 ;-0.0295 ;-0.0295\end{array}$ \\
\hline HBB & $\begin{array}{l}\mathrm{Br}(2) ; \operatorname{Br}\left(2^{\prime}\right) ; \operatorname{Br}(4) ; \operatorname{Br}\left(4^{\prime}\right) ; \operatorname{Br}(6) ; \\
\operatorname{Br}\left(6^{\prime}\right) ; \mathrm{C}(3) ; \mathrm{C}\left(3^{\prime}\right) ; \mathrm{C}(5) ; \mathrm{C}\left(5^{\prime}\right) ; \\
\mathrm{C}(7) ; \mathrm{C}\left(7^{\prime}\right)\end{array}$ & $\begin{array}{l}0.0814 ; 0.0814 ; 0.0795 ; 0.0795 ; \\
0.0795 ; 0.0795 ;-0.0370 ;-0.0370 ;- \\
0.0325 ;-0.0325 ;-0.0370 ;-0.0370\end{array}$ \\
\hline DBDE & $\mathrm{O}(1) ; \mathrm{Br}(4) ; \mathrm{Br}\left(4^{\prime}\right) ; \mathrm{C}(5) ; \mathrm{C}\left(5^{\prime}\right)$ & $\begin{array}{l}-0.1001 ; 0.0677 ; 0.0677 ;-0.0324 ;- \\
0.0324\end{array}$ \\
\hline TBDE & $\begin{array}{l}\mathrm{Br}(2) ; \mathrm{Br}\left(2^{\prime}\right) ; \mathrm{Br}(4) ; \mathrm{Br}\left(4^{\prime}\right) ; \mathrm{C}(3) ; \\
\mathrm{C}\left(3^{\prime}\right) ; \mathrm{C}(5) ; \mathrm{C}\left(5^{\prime}\right)\end{array}$ & $\begin{array}{l}0.0857 ; 0.0846 ; 0.0709 ; 0.0708 ;- \\
0.0458 ;-0.0457 ;-0.0321 ;-0.0320\end{array}$ \\
\hline HBDE & $\begin{array}{l}\mathrm{Br}(2) ; \operatorname{Br}\left(2^{\prime}\right) ; \operatorname{Br}(4) ; \operatorname{Br}\left(4^{\prime}\right) ; \operatorname{Br}(6) ; \\
\operatorname{Br}\left(6^{\prime}\right) ; C(3) ; \mathrm{C}\left(3^{\prime}\right) ; \mathrm{C}(5) ; \mathrm{C}\left(5^{\prime}\right) ; \\
\mathrm{C}(7) ; \mathrm{C}\left(7^{\prime}\right)\end{array}$ & $\begin{array}{l}0.0845 ; 0.0843 ; 0.0731 ; 0.0733 ; \\
0.0799 ; 0.0799 ;-0.0466 ;-0.0467 ;- \\
0.0326 ;-0.0325 ;-0.0446 ;-0.0445\end{array}$ \\
\hline DBBA & $\begin{array}{l}\mathrm{O}(1) ; \mathrm{O}\left(1^{\prime}\right) ; \mathrm{Br}(2) ; \mathrm{Br}\left(2^{\prime}\right) ; \mathrm{C}(3) ; \\
\mathrm{C}\left(3^{\prime}\right) ;\end{array}$ & $\begin{array}{l}-0.1478 ;-0.1475 ; 0.0576 ; 0.0531 ;- \\
0.0498 ;-0.0513 ;\end{array}$ \\
\hline TriBBA & $\begin{array}{l}\mathrm{O}(1) ; \mathrm{O}\left(1^{\prime}\right) ; \mathrm{Br}(2) ; \mathrm{Br}\left(2^{\prime}\right) ; \mathrm{C}(3) ; \\
\mathrm{C}\left(3^{\prime}\right) ; \mathrm{Br}\left(6^{\prime}\right) ; \mathrm{C}(5)\end{array}$ & $\begin{array}{l}-0.1471 ;-0.1525 ; 0.0757 ; 0.0591 ;- \\
0.0434 ;-0.0494 ; 0.0537 ;-0.0434\end{array}$ \\
\hline TBBA & $\begin{array}{l}\mathrm{O}(1) ; \mathrm{O}\left(1^{\prime}\right) ; \mathrm{Br}(2) ; \mathrm{Br}\left(2^{\prime}\right) ; \mathrm{C}(3) \\
\mathrm{C}\left(3^{\prime}\right) ; \mathrm{Br}(6) ; \mathrm{Br}\left(6^{\prime}\right) ; \mathrm{C}(5) ; \mathrm{C}\left(5^{\prime}\right)\end{array}$ & $\begin{array}{l}-0.1520 ;-0.1521 ; 0.0598 ; 0.0550 ;- \\
0.0503 ;-0.0521 ; 0.0733 ; 0.0733 ;- \\
0.0447 ;-0.0433\end{array}$ \\
\hline BMBPE & $\begin{array}{l}\mathrm{O}(1) ; \mathrm{O}\left(1^{\prime}\right) ; \mathrm{Br}(4) ; \mathrm{Br}\left(4^{\prime}\right) ; \mathrm{C}(5) ; \\
\mathrm{C}\left(5^{\prime}\right)\end{array}$ & $\begin{array}{l}-0.0738 ;-0.0738 ; 0.060 ; 0.060 ;- \\
0.0348 ;-0.0348\end{array}$ \\
\hline BDBPE & $\begin{array}{l}\mathrm{O}(1) ; \mathrm{O}\left(1^{\prime}\right) ; \mathrm{Br}(2) ; \operatorname{Br}\left(2^{\prime}\right) ; \mathrm{C}(3) \\
\mathrm{C}\left(3^{\prime}\right) ; \mathrm{Br}(4) ; \mathrm{Br}\left(4^{\prime}\right) ; \mathrm{C}(5) ; \mathrm{C}\left(5^{\prime}\right)\end{array}$ & $\begin{array}{l}-0.0927 ;-0.0910 ; 0.0853 ; 0.0683 ;- \\
0.0428 ;-0.0434 ; 0.0644 ; 0.0649 ;- \\
0.0332 ;-0.0330\end{array}$ \\
\hline BTBPE & $\begin{array}{l}\mathrm{O}(1) ; \mathrm{O}\left(1^{\prime}\right) ; \mathrm{Br}(2) ; \mathrm{Br}\left(2^{\prime}\right) ; \mathrm{C}(3) ; \\
\mathrm{C}\left(3^{\prime}\right) ; \mathrm{Br}(4) ; \mathrm{Br}\left(4^{\prime}\right) ; \mathrm{C}(5) ; \mathrm{C}\left(5^{\prime}\right) ; \\
\mathrm{Br}(6) ; \mathrm{Br}\left(6^{\prime}\right) ; \mathrm{C}(7) ; \mathrm{C}\left(7^{\prime}\right)\end{array}$ & $\begin{array}{l}-0.0990 ;-0.0935 ; 0.0668 ; 0.0719 ;- \\
0.0433 ;-0.0442 ; 0.0663 ; 0.0675 ;- \\
0.0334 ;-0.0348 ; 0.0881 ; 0.0888 ;- \\
0.0435 ;-0.0404\end{array}$ \\
\hline DBCD & $\mathrm{Br}(1) ; \mathrm{Br}(2) ; \mathrm{C}(3) ; \mathrm{C}(4)$ & $0.0241 ; 0.0077 ;-0.0303 ;-0.0309$ \\
\hline TBCD & $\begin{array}{l}\mathrm{Br}(1) ; \mathrm{Br}(2) ; \mathrm{Br}(3) ; \mathrm{Br}(4) ; \mathrm{C}(5) ; \\
\mathrm{C}(6) ; \mathrm{C}(7) ; \mathrm{C}(8)\end{array}$ & $\begin{array}{c}0.0334 ; 0.0294 ; 0.0228 ; 0.0200 ;- \\
0.0298 ;-0.0290 ;-0.0319 ;-0.0346\end{array}$ \\
\hline HBCD & $\begin{array}{l}\mathrm{Br}(1) ; \mathrm{Br}(2) ; \mathrm{Br}(3) ; \mathrm{Br}(4) ; \mathrm{Br}(5) ; \\
\mathrm{Br}(6) ; \mathrm{C}(7) ; \mathrm{C}(8) ; \mathrm{C}(9) ; \mathrm{C}(10) ; \\
\mathrm{C}(11) ; \mathrm{C}(12)\end{array}$ & $\begin{array}{l}0.0366 ; 0.0250 ; 0.0416 ; 0.0276 ; \\
0.0298 ; 0.0372 ;-0.0271 ;-0.0282 ;- \\
0.0280 ;-0.0343 ;-0.0289 ;-0.0312\end{array}$ \\
\hline
\end{tabular}


Table 3

Calculated excitation energies of molecules as photon absorption energy $E$ (in $\mathrm{eV}$ ) and the oscillator strength $(f)$ of the five lowest excited states of selected BFRs and their nonbrominated congeners in the gaseous phase.

$E($ in eV)

$f \quad E($ in $\mathrm{eV})$

$f$

$E$ (in eV)

biphenyl

DBB

TBB

\begin{tabular}{lcccccc}
\hline S1 & 4.16 & 0.000000 & 3.17 & 0.000000 & 4.12 & 0.000000 \\
\hline S2 & 4.27 & 0.528043 & 3.79 & 0.000000 & 4.18 & 0.000000 \\
\hline S3 & 4.44 & 0.005237 & 4.13 & 0.738376 & 4.26 & 0.000000 \\
\hline S4 & 4.82 & 0.000001 & 4.13 & 0.000000 & 4.35 & 0.000000 \\
\hline S5 & 5.09 & 0.045887 & 4.25 & 0.000000 & 4.40 & 0.000000
\end{tabular}

HBB

Diphenylether

DBDE

\begin{tabular}{lcccccc}
\hline S1 & 1.67 & 0.000000 & 4.04 & 0.000000 & 3.81 & 0.000000 \\
\hline S2 & 2.24 & 0.000000 & 4.12 & 0.000000 & 3.91 & 0.000000 \\
\hline S3 & 2.35 & 0.212599 & 4.35 & 0.000000 & 4.12 & 0.011069 \\
\hline S4 & 2.43 & 0.000000 & 4.41 & 0.000000 & 4.14 & 0.000000 \\
\hline S5 & 2.49 & 0.021078 & 4.43 & 0.010764 & 4.20 & 0.001869
\end{tabular}

TBDE

HBDE

Bisphenol A

\begin{tabular}{lcccccc}
\hline S1 & 3.86 & 0.000000 & 3.56 & 0.000000 & 4.13 & 0.026168 \\
\hline S2 & 3.96 & 0.000000 & 3.70 & 0.000000 & 4.22 & 0.000329 \\
\hline S3 & 4.04 & 0.000000 & 3.71 & 0.022974 & 4.52 & 0.049700 \\
\hline S4 & 4.07 & 0.000000 & 3.81 & 0.000272 & 4.58 & 0.001626 \\
\hline S5 & 4.12 & 0.025349 & 3.85 & 0.0000000 & 4.74 & 0.010612
\end{tabular}

DBBA

TriBBA

TBBA

\begin{tabular}{lcccccc}
\hline S1 & 3.93 & 0.000000 & 3.83 & 0.000000 & 3.72 & 0.000000 \\
\hline S2 & 4.02 & 0.000000 & 3.95 & 0.000000 & 3.75 & 0.000000 \\
\hline S3 & 4.07 & 0.000000 & 3.95 & 0.006451 & 3.79 & 0.000000 \\
\hline S4 & 4.18 & 0.000000 & 4.01 & 0.000000 & 3.84 & 0.005748 \\
\hline S5 & 4.23 & 0.017844 & 4.04 & 0.000000 & 3.86 & 0.002312
\end{tabular}




\begin{tabular}{|c|c|c|c|c|c|c|}
\hline S1 & 4.36 & 0.001883 & 3.96 & 0.000000 & 4.14 & 0.000000 \\
\hline $\mathbf{S 2}$ & 4.51 & 0.003150 & 3.96 & 0.000000 & 4.17 & 0.000000 \\
\hline S3 & 4.55 & 0.003084 & 4.17 & 0.000000 & 4.25 & 0.000000 \\
\hline S4 & 4.83 & 0.005917 & 4.18 & 0.000000 & 4.30 & 0.000000 \\
\hline \multirow[t]{2}{*}{ S5 } & 4.85 & 0.013199 & 4.18 & 0.000315 & 4.36 & 0.000000 \\
\hline & \multicolumn{2}{|c|}{ TBTBPE } & \multicolumn{2}{|c|}{ cyclododecane } & \multicolumn{2}{|c|}{ DBCD } \\
\hline S1 & 3.80 & 0.000000 & 8.12 & 0.023689 & 5.29 & 0.000000 \\
\hline $\mathbf{S 2}$ & 3.89 & 0.000000 & 8.15 & 0.000128 & 5.36 & 0.000000 \\
\hline S3 & 3.90 & 0.000713 & 8.34 & 0.003114 & 5.48 & 0.000000 \\
\hline S4 & 3.98 & 0.000447 & 8.37 & 0.000475 & 5.50 & 0.003934 \\
\hline \multirow[t]{2}{*}{ S5 } & 3.98 & 0.000000 & 8.40 & 0.009544 & 5.52 & 0.000000 \\
\hline & \multicolumn{2}{|c|}{ TBCD } & \multicolumn{2}{|c|}{ HBCD } & & \\
\hline S1 & 4.94 & 0.000000 & 4.93 & 0.000000 & & \\
\hline $\mathbf{S 2}$ & 5.11 & 0.000000 & 5.13 & 0.000000 & & \\
\hline $\mathbf{S 3}$ & 5.13 & 0.000932 & 5.13 & 0.000847 & & \\
\hline S4 & 5.18 & 0.000000 & 5.18 & 0.000000 & & \\
\hline S5 & 5.21 & 0.000000 & 5.20 & 0.000000 & & \\
\hline
\end{tabular}




\section{Table 4}

Calculated excitation energies of molecules as photon absorption energy $E$ (in $\mathrm{eV}$ ) and the oscillator strength $(f)$ of the five lowest excited states of selected BFRs and their nonbrominated congeners in the aqueous phase.

$E$ (in eV)

$$
f \quad E(\text { in } \mathrm{eV})
$$

$$
f
$$

$$
E \text { (in eV) }
$$

\section{DBB}

4.13

0.756427

4.14

0.000000

4.25

4.36

4.40

0.000010

4.80

diphenylether

DBDE

\begin{tabular}{lcccccc}
\hline S1 & 1.17 & 0.000000 & 4.08 & 0.000000 & 4.16 & 0.009224 \\
\hline S2 & 1.50 & 0.000000 & 4.14 & 0.000000 & 4.41 & 0.001709 \\
\hline S3 & 1.69 & 0.008854 & 4.36 & 0.000000 & 4.49 & 0.254724 \\
\hline S4 & 1.86 & 0.000000 & 4.45 & 0.000000 & 4.65 & 0.001598 \\
\hline S5 & 1.89 & 0.000000 & 4.45 & 0.011504 & 4.71 & 0.000346
\end{tabular}

TBDE

HBDE

Bisphenol A

\begin{tabular}{lcccccc}
\hline S1 & 3.88 & 0.000000 & 3.57 & 0.000000 & 4.14 & 0.025994 \\
\hline S2 & 3.98 & 0.000000 & 3.72 & 0.024709 & 4.23 & 0.000373 \\
\hline S3 & 4.05 & 0.000000 & 3.72 & 0.000000 & 4.53 & 0.051397 \\
\hline S4 & 4.09 & 0.000000 & 3.84 & 0.000241 & 4.60 & 0.001396 \\
\hline S5 & 4.15 & 0.024313 & 3.86 & 0.000000 & 4.75 & 0.010763
\end{tabular}

DBBA

TriBBA

TBBA

\begin{tabular}{lcccccc}
\hline S1 & 3.95 & 0.000000 & 3.83 & 0.000000 & 3.82 & 0.000000 \\
\hline S2 & 4.00 & 0.000000 & 3.93 & 0.005356 & 3.84 & 0.000000 \\
\hline S3 & 4.05 & 0.000000 & 3.94 & 0.000000 & 3.96 & 0.009846 \\
\hline S4 & 4.20 & 0.000000 & 3.97 & 0.000000 & 3.96 & 0.000543 \\
\hline S5 & 4.24 & 0.015757 & 4.05 & 0.000000 & 3.97 & 0.000000
\end{tabular}




\begin{tabular}{|c|c|c|c|c|c|c|}
\hline S1 & 4.37 & 0.001973 & 3.97 & 0.000000 & 3.94 & 0.000000 \\
\hline S2 & 4.52 & 0.003131 & 3.97 & 0.000000 & 3.94 & 0.000000 \\
\hline S3 & 4.56 & 0.003101 & 4.18 & 0.000000 & 4.04 & 0.000000 \\
\hline S4 & 4.84 & 0.005482 & 4.19 & 0.000230 & 4.05 & 0.000000 \\
\hline \multirow[t]{2}{*}{ S5 } & 4.86 & 0.014184 & 4.19 & 0.000000 & 4.11 & 0.000001 \\
\hline & \multicolumn{2}{|c|}{ ВTBPE } & \multicolumn{2}{|c|}{ cyclododecane } & \multicolumn{2}{|c|}{ DBCD } \\
\hline S1 & 3.84 & 0.000000 & 8.14 & 0.023283 & 5.28 & 0.000000 \\
\hline S2 & 3.86 & 0.000000 & 8.17 & 0.000113 & 5.36 & 0.000000 \\
\hline S3 & 3.94 & 0.003183 & 8.35 & 0.003426 & 5.49 & 0.004894 \\
\hline S4 & 4.00 & 0.000524 & 8.38 & 0.000767 & 5.49 & 0.000000 \\
\hline \multirow[t]{2}{*}{ S5 } & 4.03 & 0.000000 & 8.42 & 0.009694 & 5.50 & 0.000000 \\
\hline & \multicolumn{2}{|c|}{ TBCD } & \multicolumn{2}{|c|}{ HBCD } & & \\
\hline S1 & 4.89 & 0.000000 & 4.88 & 0.000000 & & \\
\hline S2 & 5.06 & 0.000000 & 5.05 & 0.000000 & & \\
\hline S3 & 5.11 & 0.001324 & 5.09 & 0.001339 & & \\
\hline S4 & 5.17 & 0.000000 & 5.14 & 0.000000 & & \\
\hline S5 & 5.18 & 0.000000 & 5.16 & 0.000000 & & \\
\hline
\end{tabular}




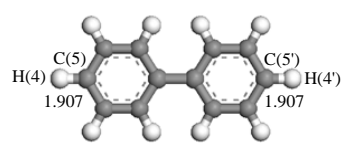

biphenyl

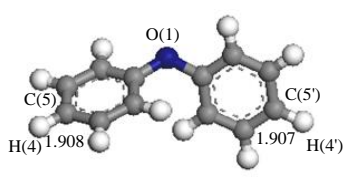

diphenylether

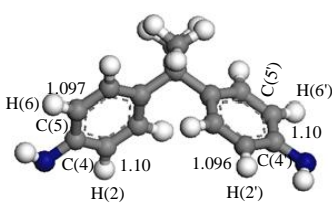

bisphenol A

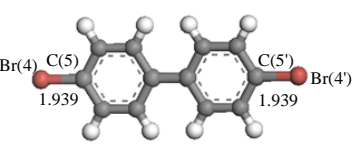

DBB

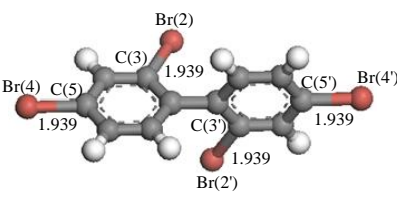

TBB

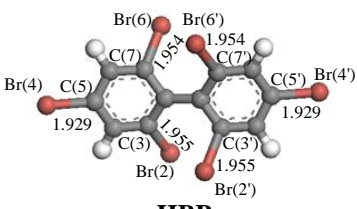

HBB

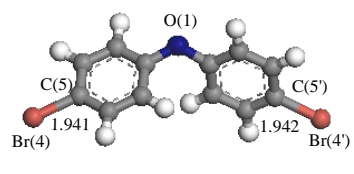

DBDE

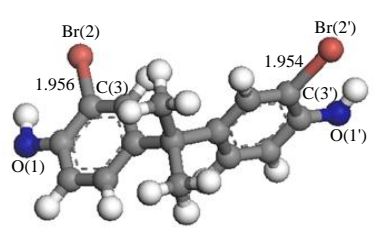

DBBA

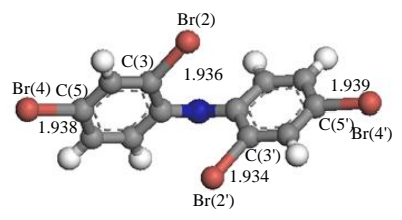

TBDE

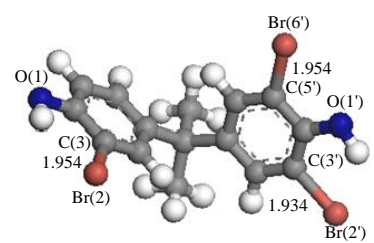

TriBBA

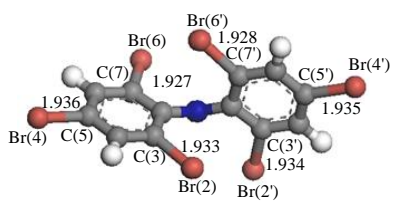

HBDE

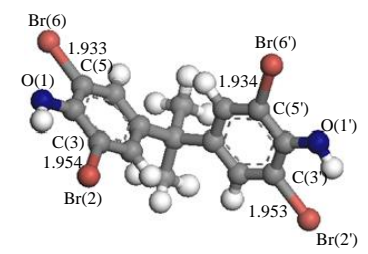

TBBA

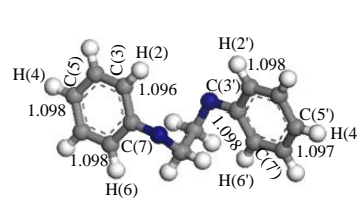

bisphenoxyethane

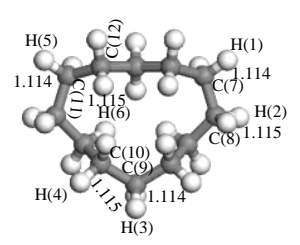

cyclododecane

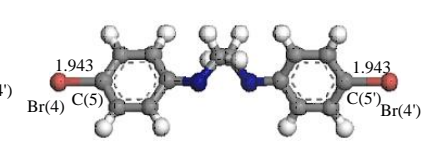

BMBPE

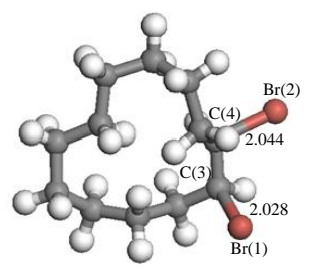

DBCD

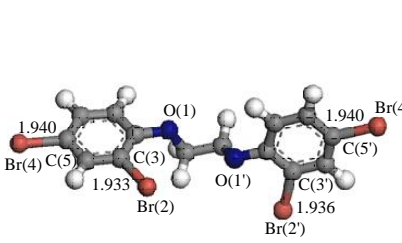

BDBPE

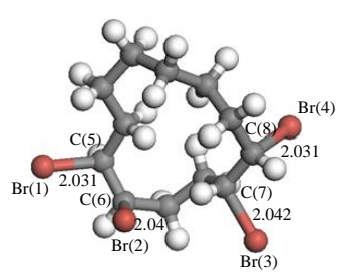

TBCD

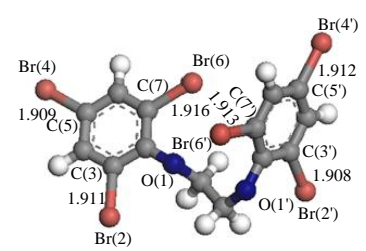

BTBPE

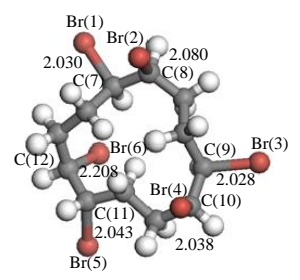

HBCD

Fig. 1. Optimised geometries of selected BFRs and their non-brominated congeners with CBr bond distance (in $\AA$ ) corresponding to the gaseous $\mathrm{S}_{0}$ state. Bromine and oxygen atoms are denoted by red and blue spheres, respectively. 


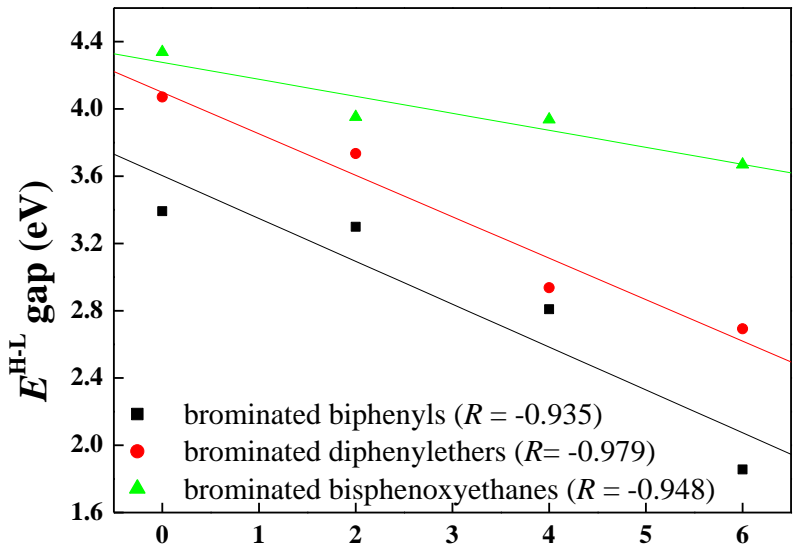

Number of $\mathrm{Br}$ atoms

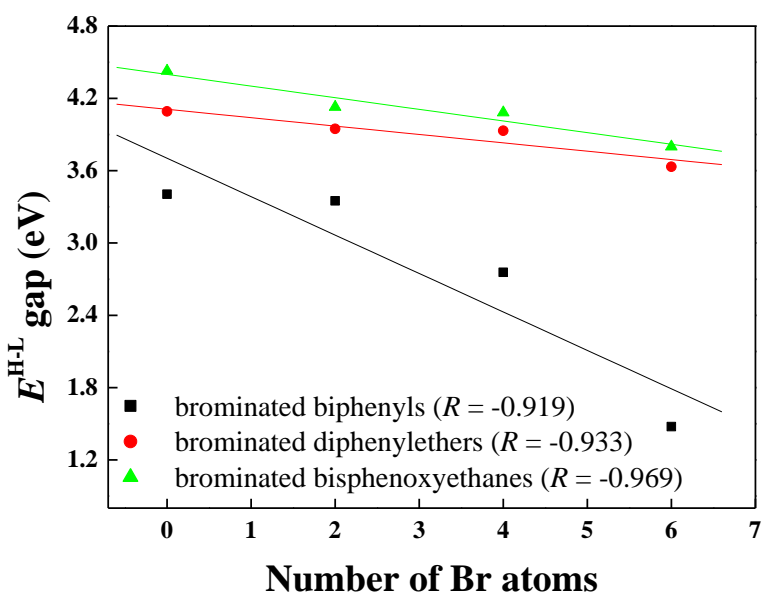

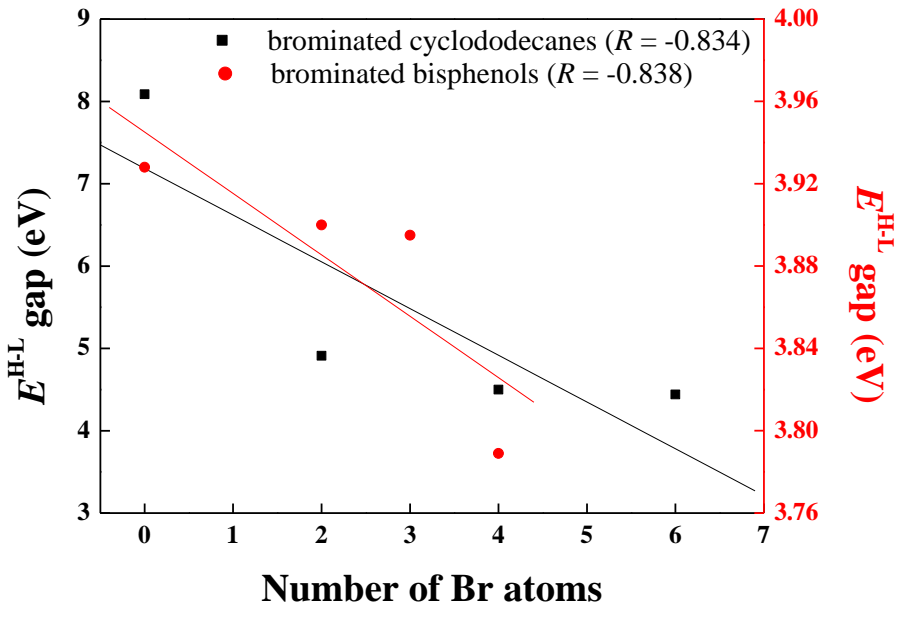

(a)

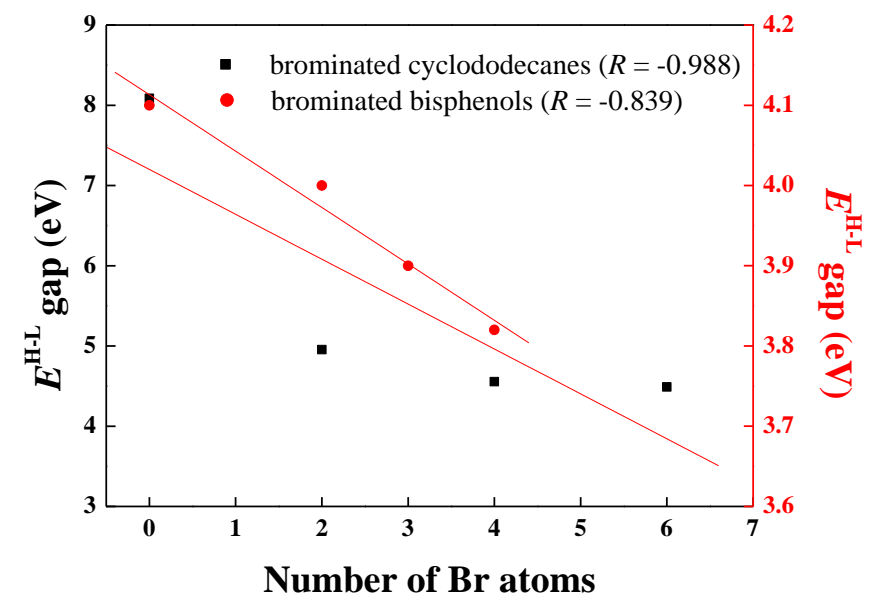

(b)

Fig. 2. Correlation between the number of $\mathrm{Br}$ atoms and calculated energy gap $E^{\mathrm{H}-\mathrm{L}}($ in $\mathrm{eV}$ ) between the frontier molecular orbitals for (a) gaseous and (b) aqueous phases. The value of $R$ depicts the degree of linearity of a trend line. 

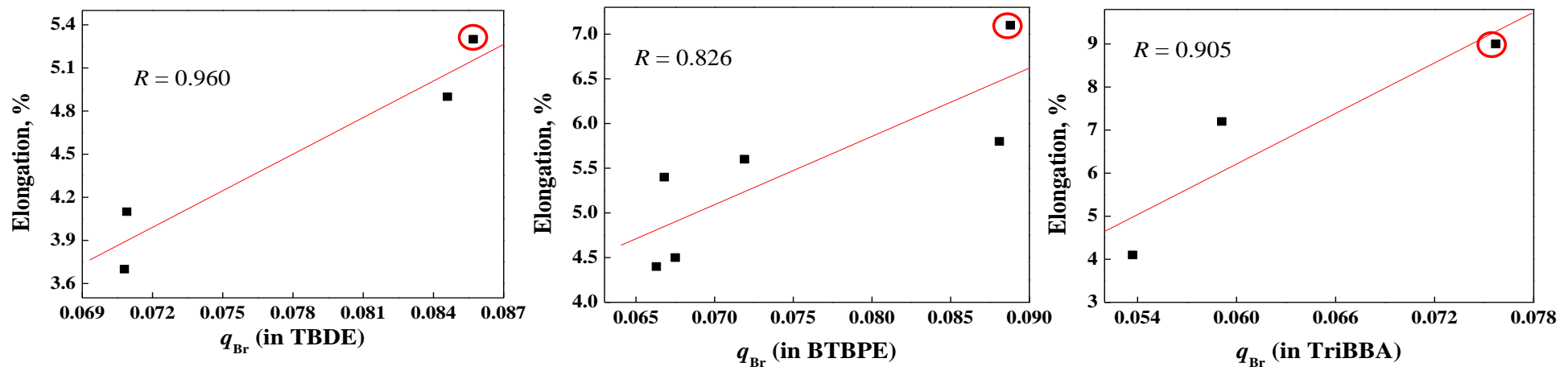

(a)
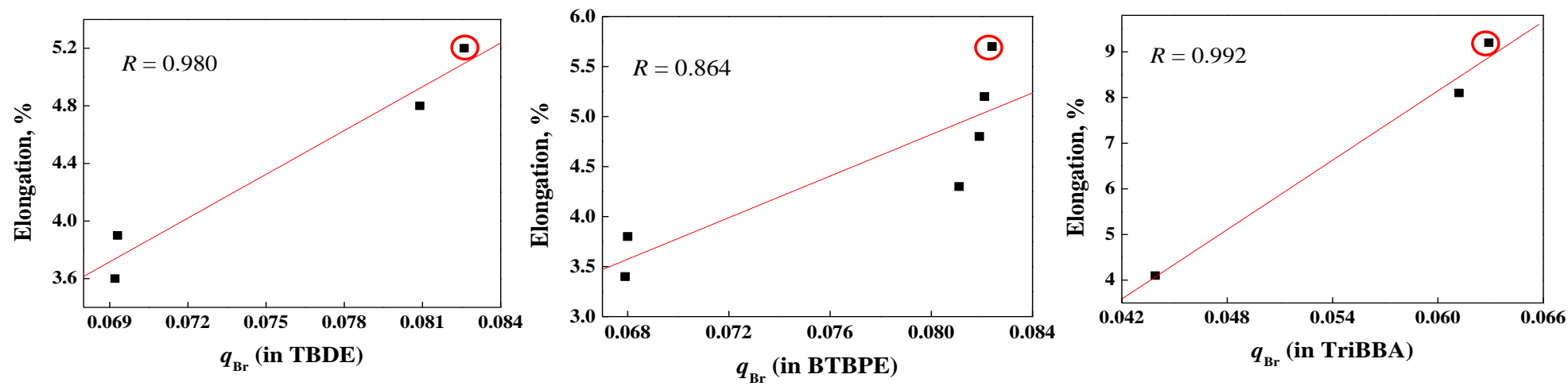

(b)

Fig. 3. Correlations between the calculated atomic charge on bromine $\left(q_{\mathrm{Br}}\right)$ in the $\mathrm{S}_{0}$ state and the percentage of elongation in C-Br bond upon the $S_{0} \rightarrow S_{1}$ transition for selected congeners of BFRs in gaseous (a) and aqueous (b) phases. The bromine atom attached at an ortho position with regard to the $\mathrm{C}-\mathrm{O}$ linkage (in TBDE and BTBPE) and hydroxyl group (in TBBA) entails the highest positive charge (encircled in red). The value of $R$ depicts the degree of linearity of a trend line. 

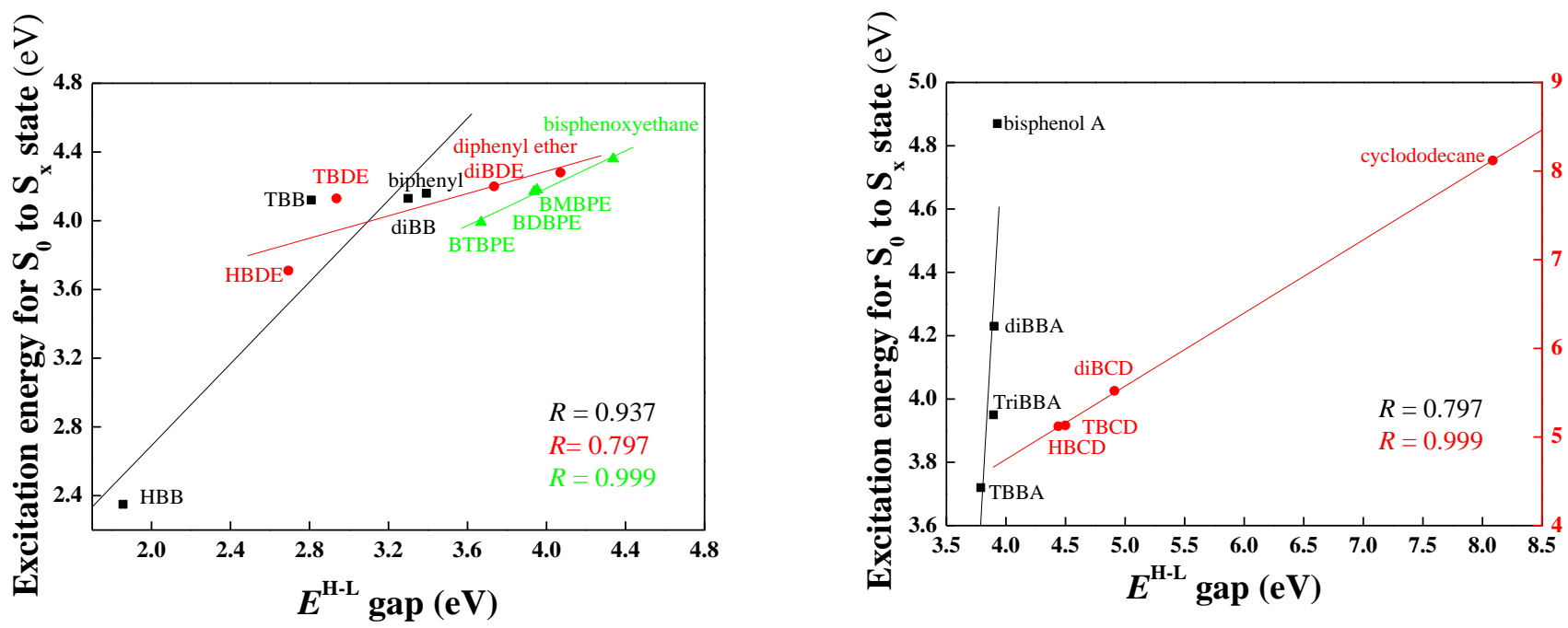

(a)
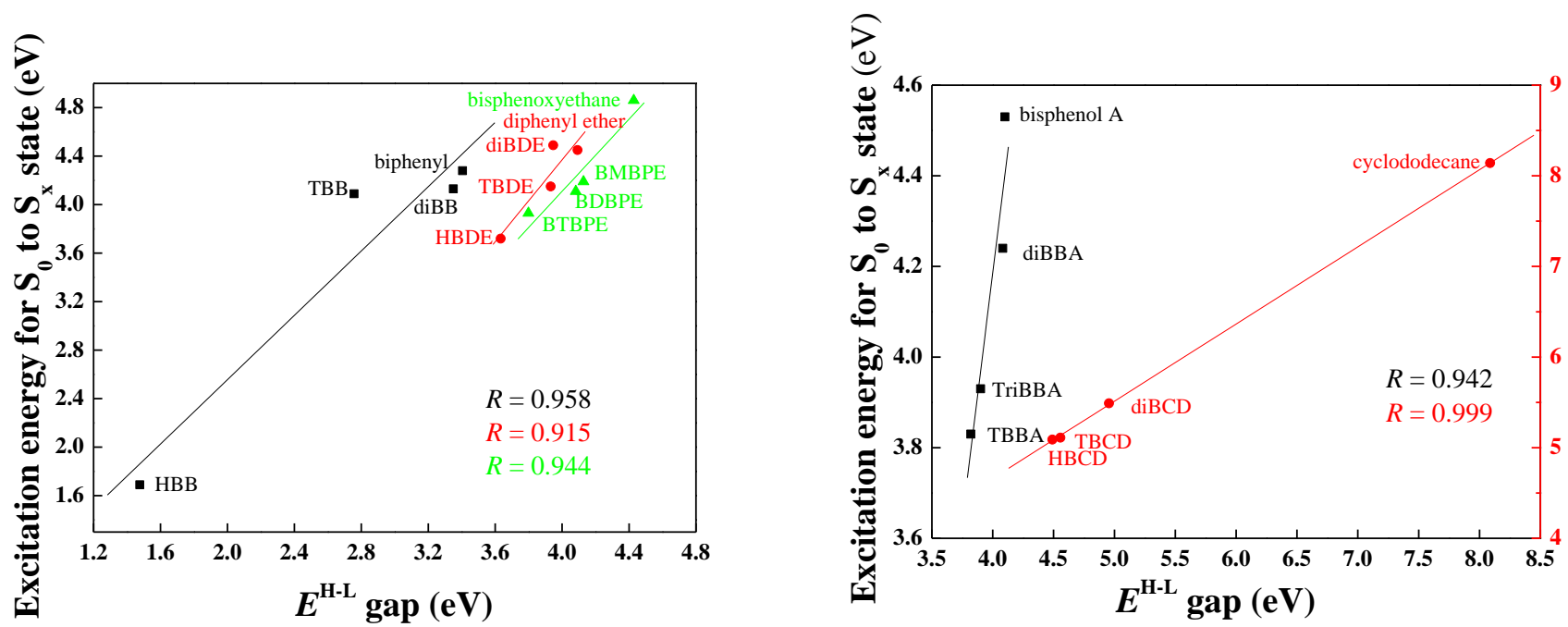

(b)

Fig. 4. Correlation between the $E^{\mathrm{H}-\mathrm{L}}$ (in eV) and the excitation energy (in eV) for the $\mathrm{S}_{0} \rightarrow \mathrm{S}_{\mathrm{x}}$ transition for brominated and non-brominated compounds in (a) gaseous and (b) aqueous phases. S $\mathrm{x}$ represents the most accessible excited state. The value of $R$ depicts the degree of linearity of a trend line. 

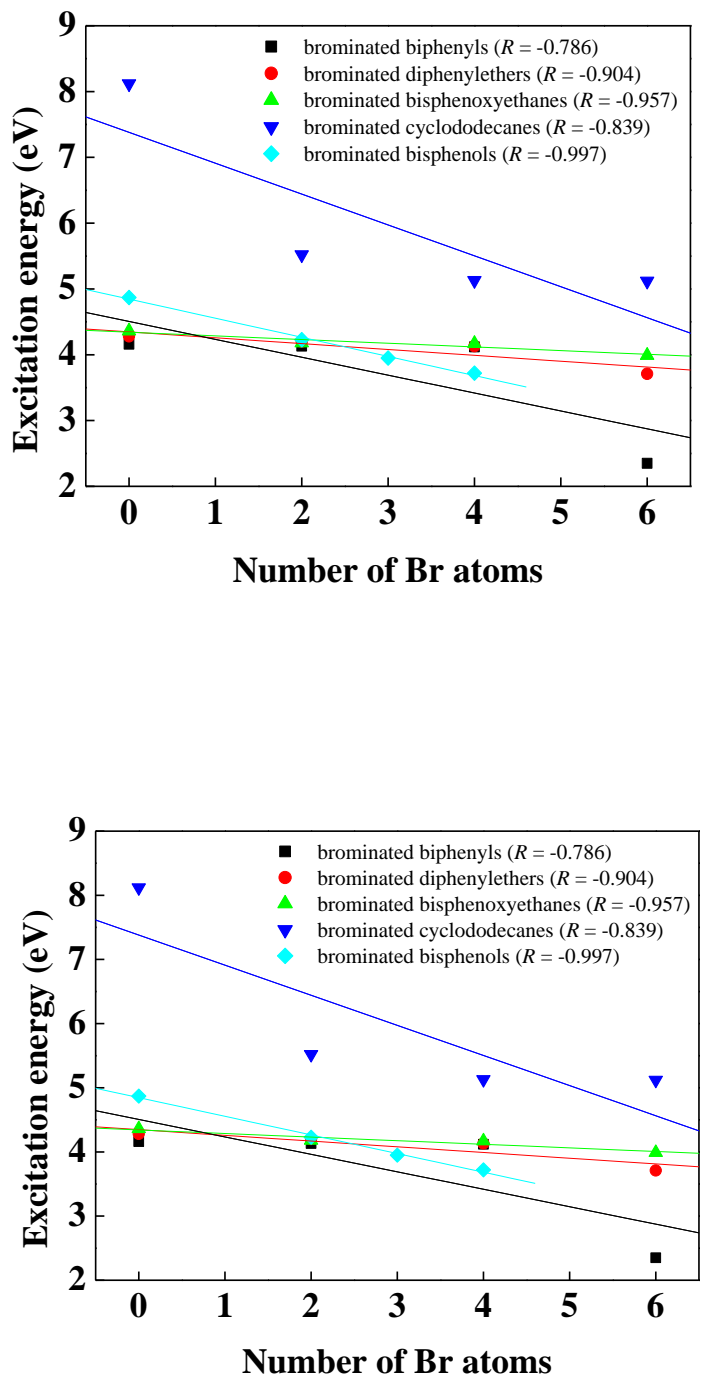

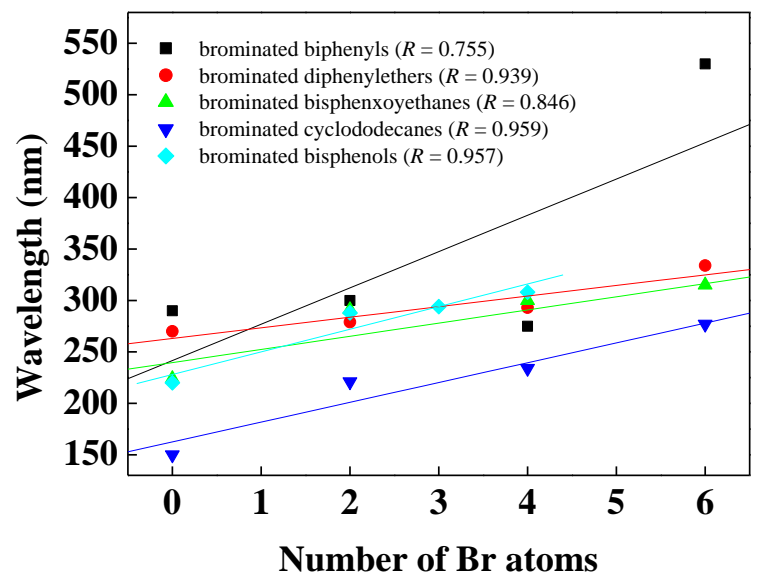

(a)

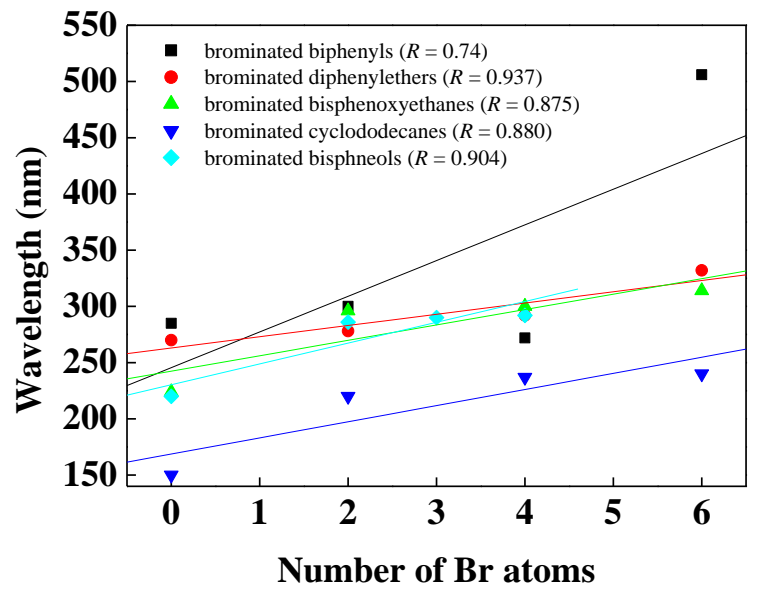

(b)

Fig. 5. Correlation between the calculated lowest excitation energy values $(\mathrm{eV})$ and the number of bromine atoms, as well as between the calculated wavelength (nm) at the maximum absorption and the number of bromine atoms in (a) gaseous and (b) aqueous phases. The value of $R$ depicts the degree of linearity of a trend line. 


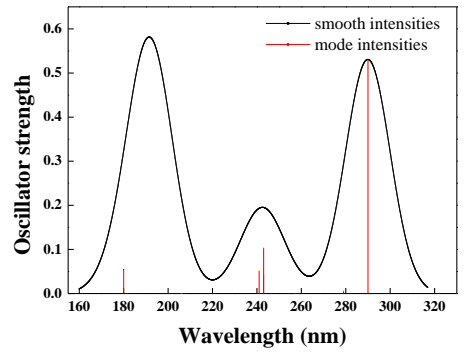

biphenyl

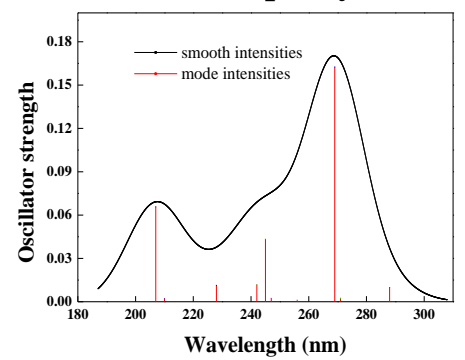

diphenylether

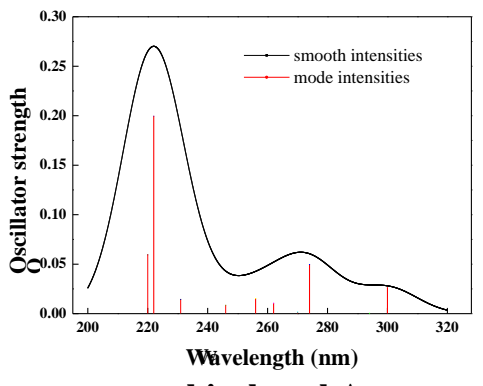

bisphenol A

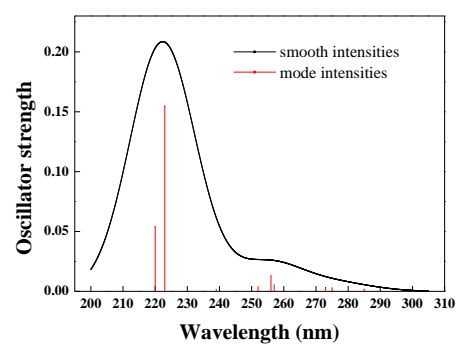

bisphenoxyethane

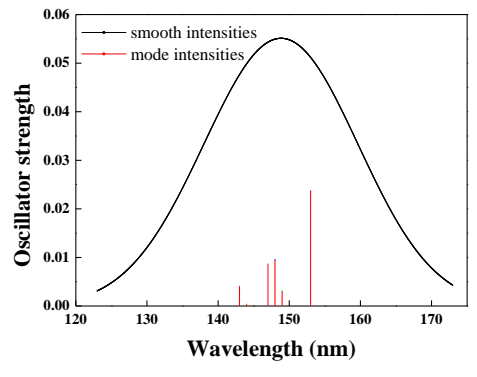

cyclododecane

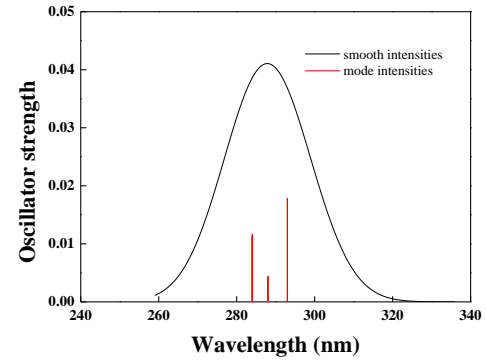

DBB

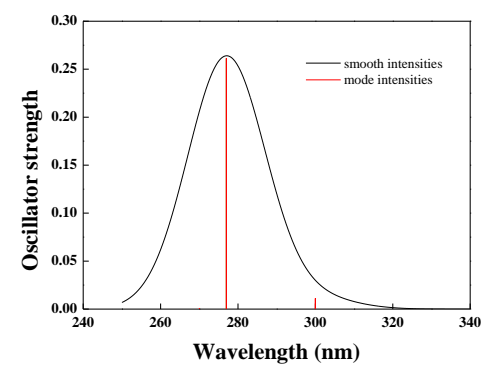

DBDE

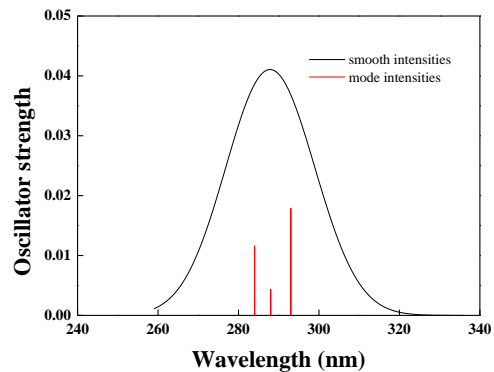

DBBA

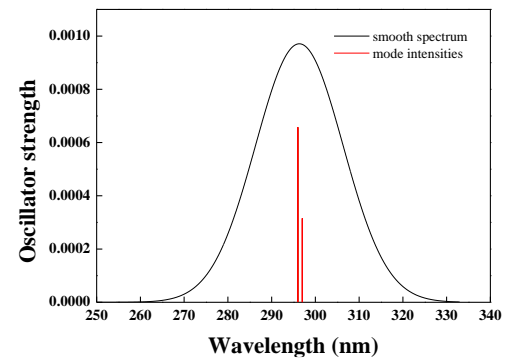

BMBPE

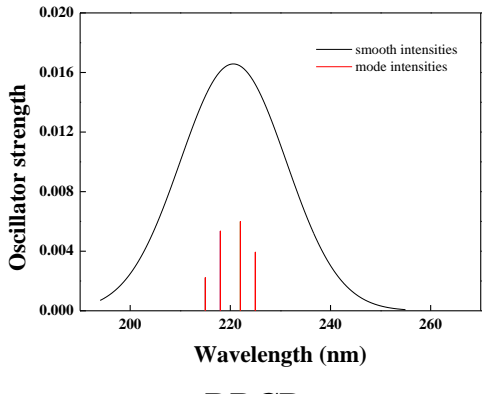

DBCD

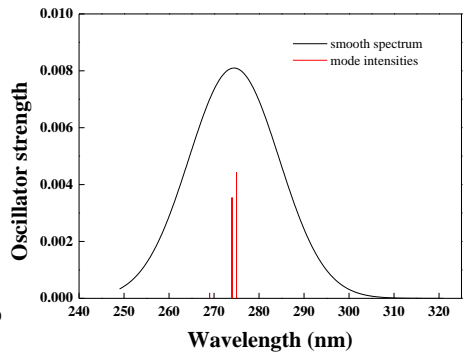

TBB

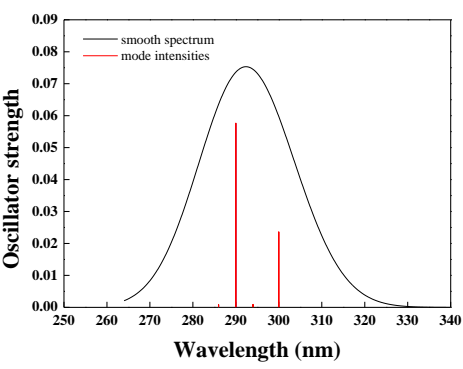

TBDE

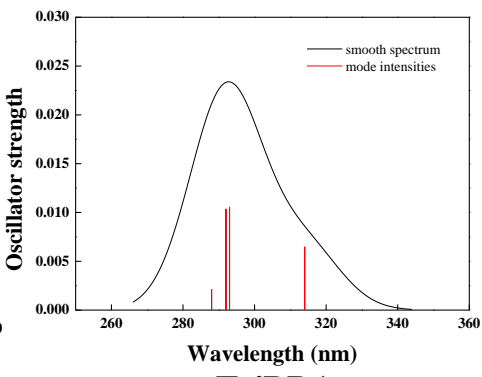

TriBBA

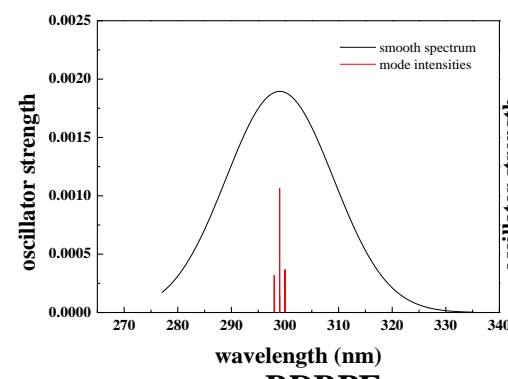

BDBPE

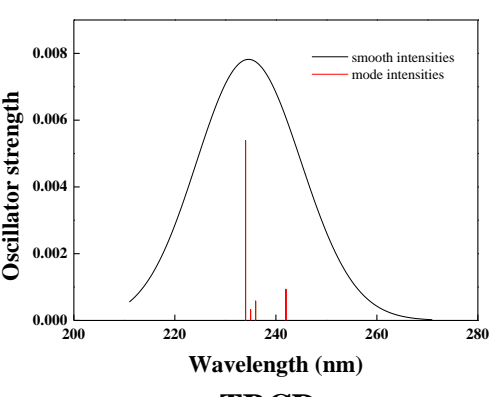

TBCD

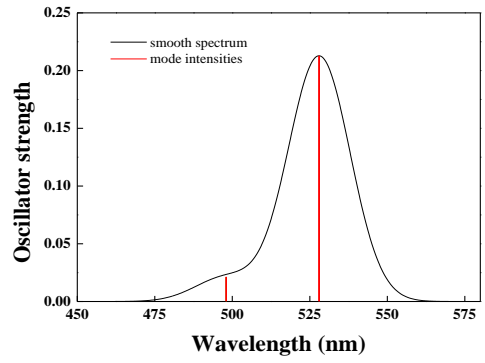

HBB

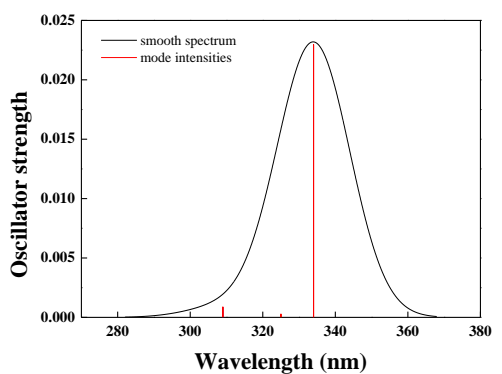

HBDE

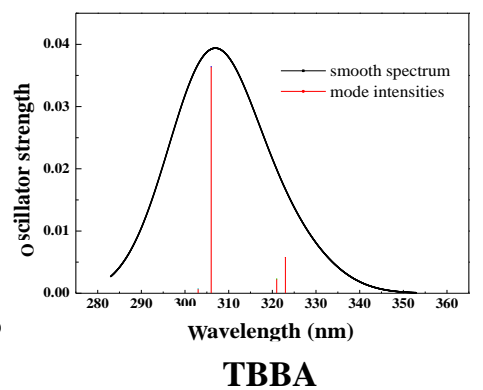

TBBA

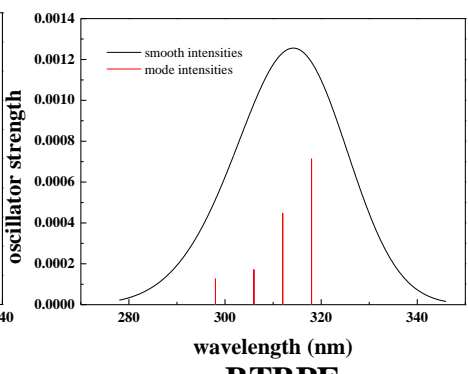

BTBPE

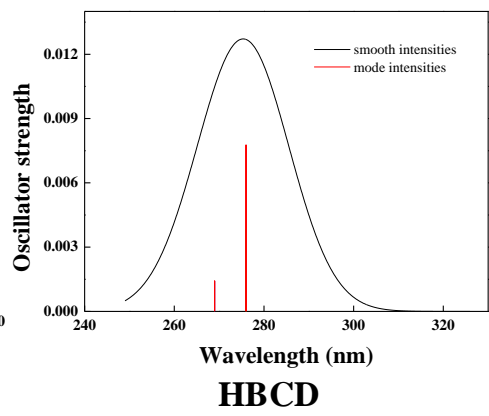

Fig. 6. The calculated gaseous-phase UV absorption spectra of studied BFRs and their nonbrominated congeners. 

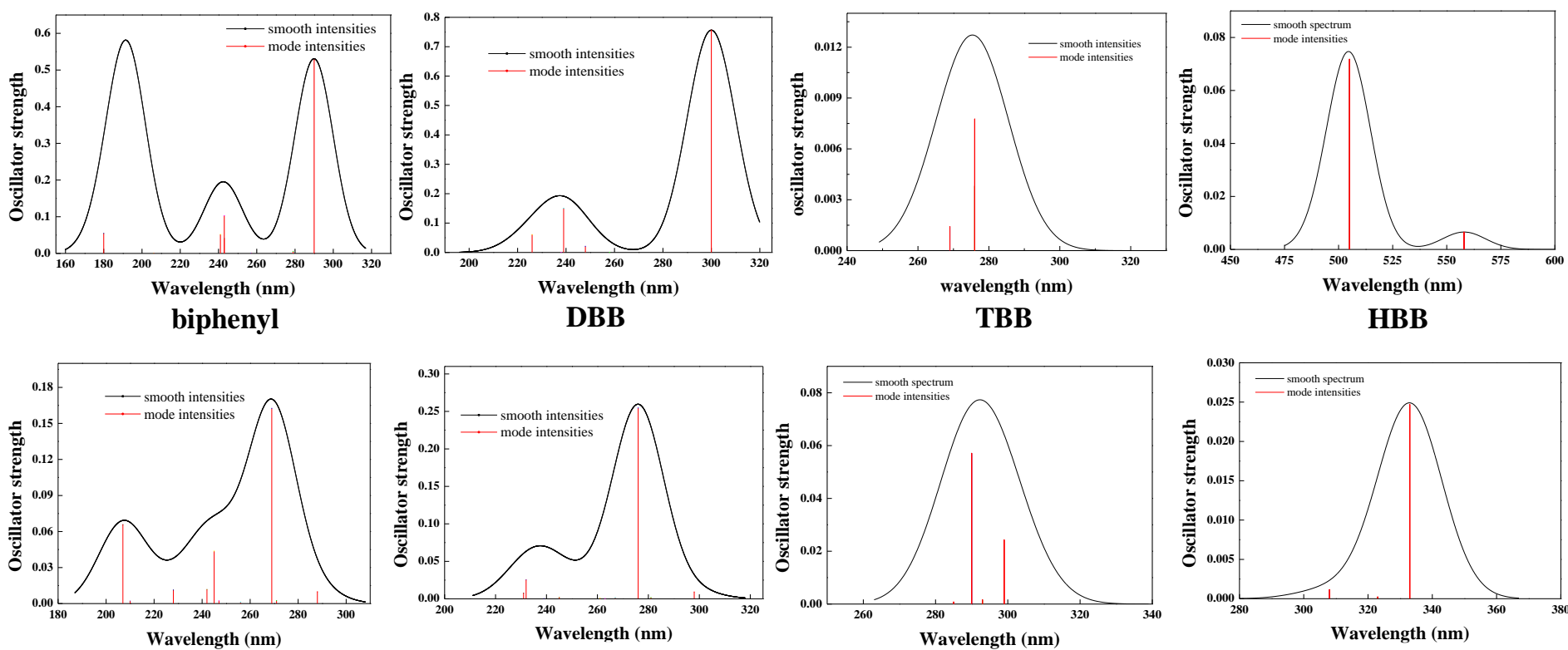

diphenylether

DBDE
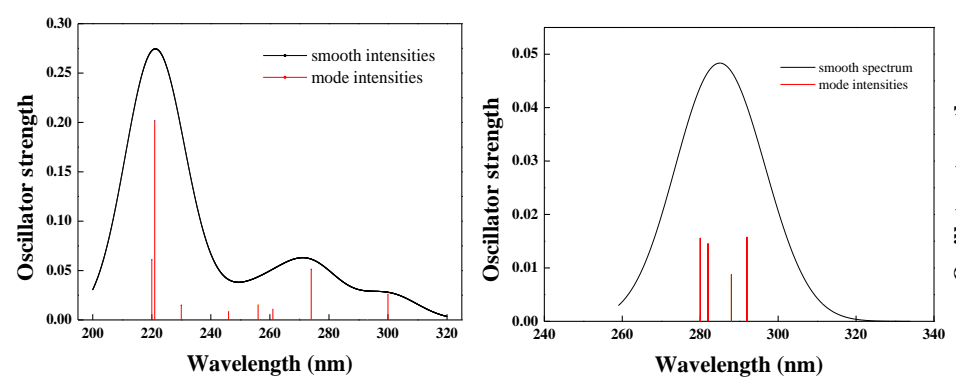

bisphenol A

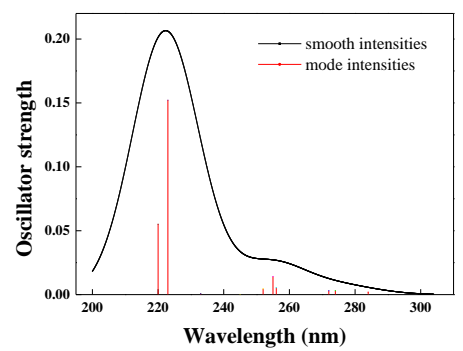

bisphenoxyethane

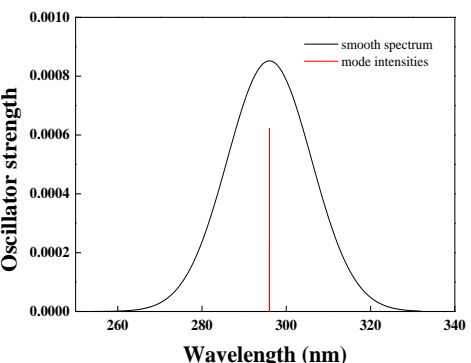

BMBPE

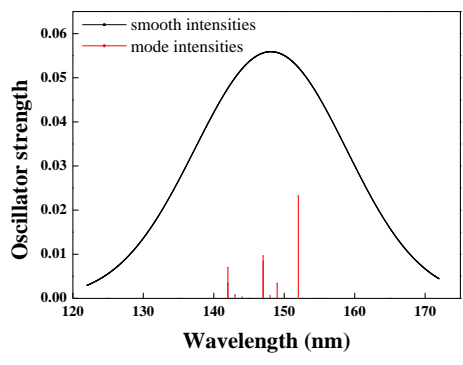

cyclododecane

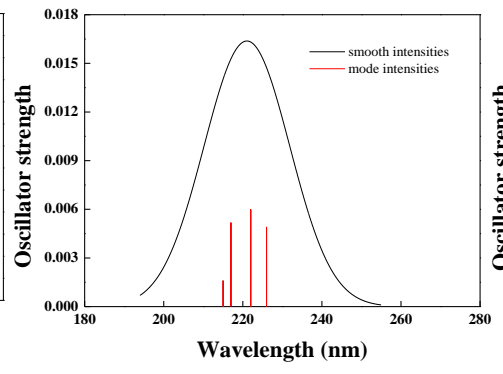

DBCD

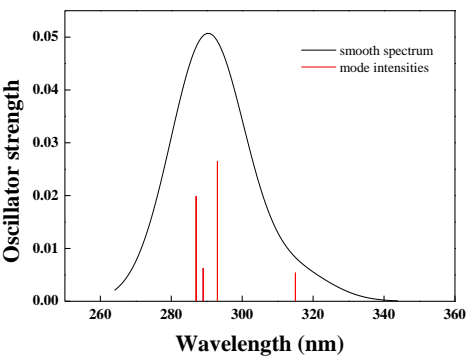

TriBBA

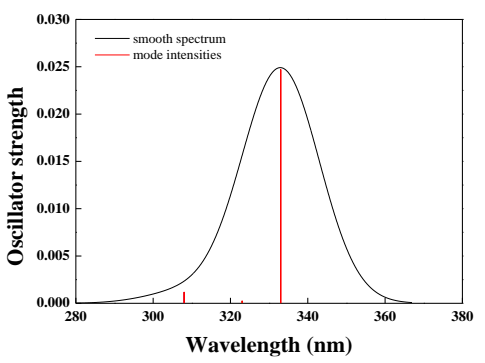

HBDE

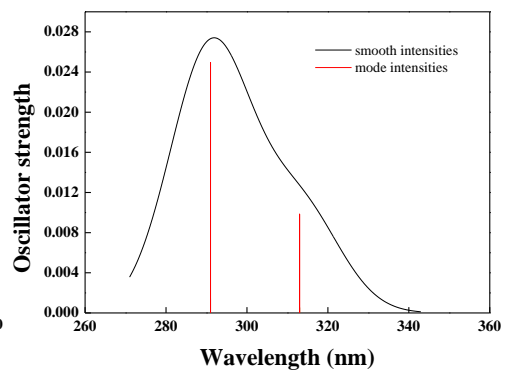

TBBA

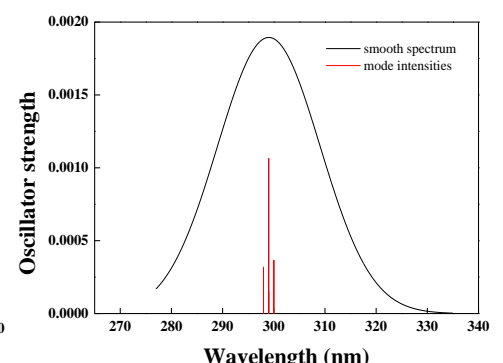

BDBPE

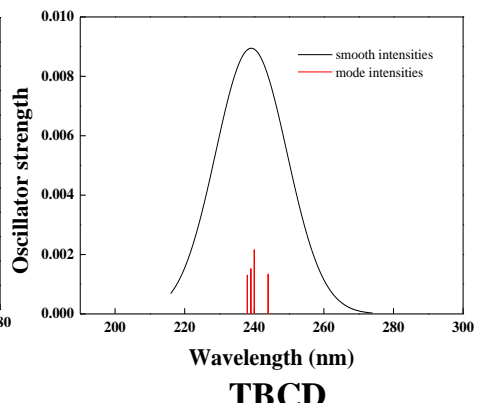

TBCD

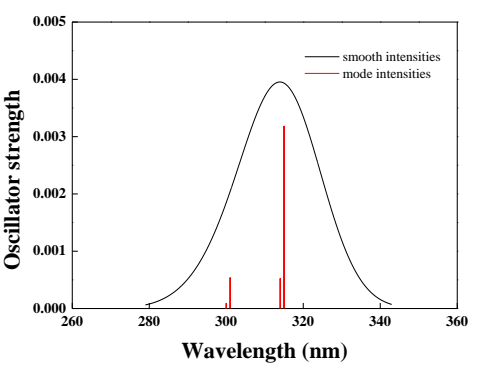

BTBPE

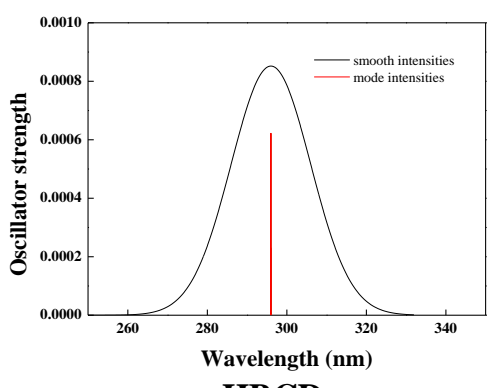

HBCD

Fig. 7. The calculated aqueous-phase UV absorption spectra of studied BFRs and their nonbrominated congeners. 

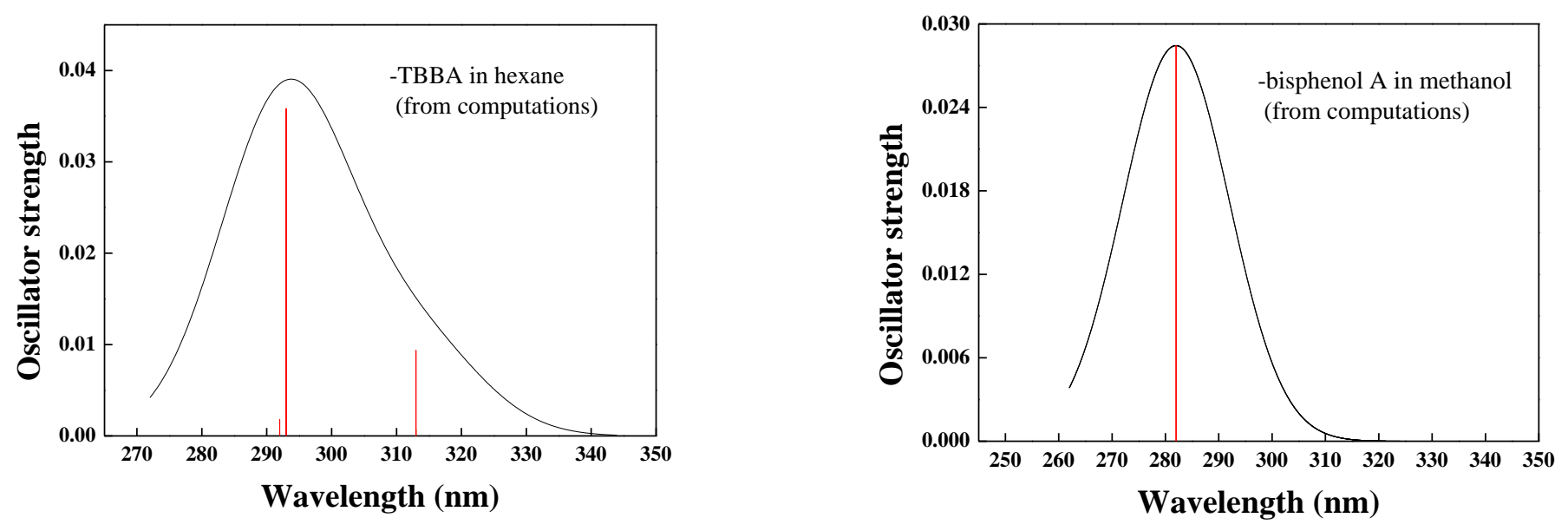

(a)
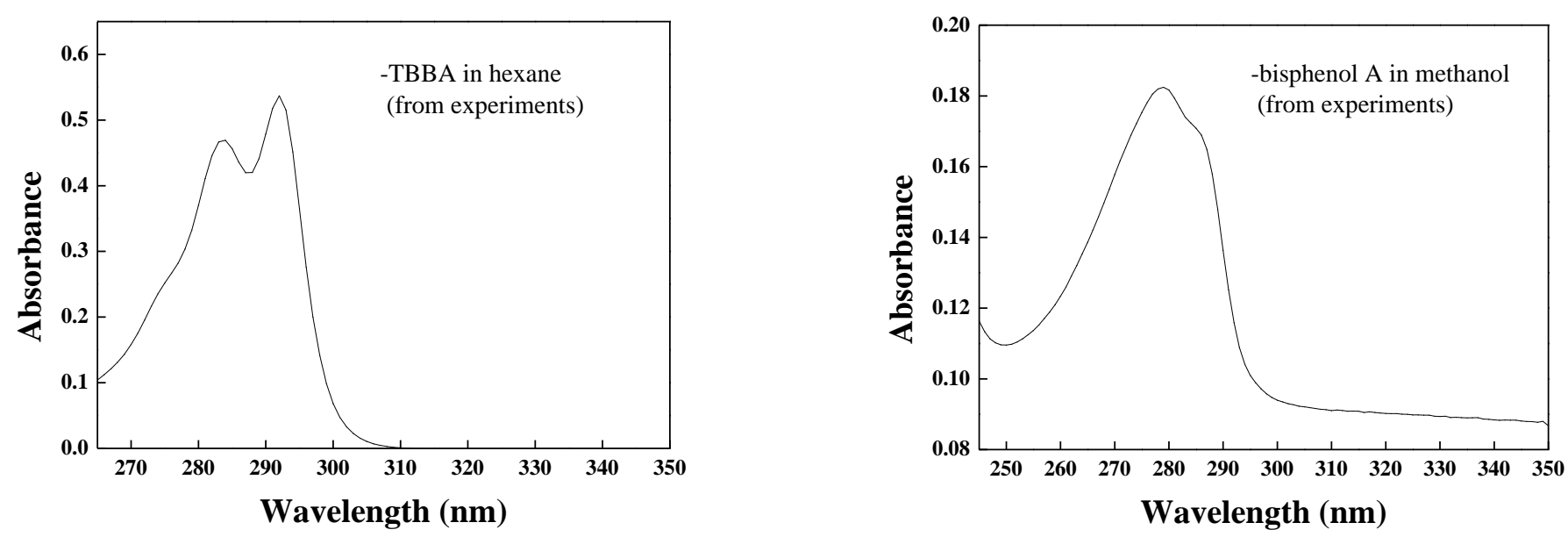

(b)

Fig. 8. UV-Vis spectra of TBBA and bisphenol A from (a) theoretical calculations and (b) experimental measurements in hexane and methanol, respectively. 